\title{
Study of the Inversion Reaction of the Lactonic Fusion on Eremanthine Derivatives
}

\author{
José C. F. Alves* and Edna C. Fantini ${ }^{\dagger}$ \\ Departamento de Química, Instituto de Ciências Exatas, Universidade Federal Rural do \\ Rio de Janeiro,23890-970 Seropédica-RJ, Brazil
}

\begin{abstract}
As $\alpha$-metileno- $\gamma$-lactonas 4(15)-diidroeremantina (8), 4(15),9(10)-tetraidroeremantina (9), isoeremantina (10), acetato alílico $\Delta^{1,10}(\mathbf{1 1}), 1(\mathrm{R}), 10(\mathrm{R})$-diidromiqueliolido (12) e $4 \alpha$-hidróxi acetato alílico $\Delta^{1,10}(\mathbf{1 3})$ foram sintetizadas a partir do produto natural abundante eremantina (1). Essas substâncias foram submetidas à reação de hidrólise com $\mathrm{KOH}$ aquoso e os sais carboxílicos dessas lactonas tiveram suas hidroxilas ativadas na posição C-6, pela formação dos respectivos mesilatos ( $\mathrm{MsCl}, \mathrm{Et}_{3} \mathrm{~N}, \mathrm{THF}$ ou DMSO) para deslocamento nucleofílico efetuado pelo grupo carboxilato. A utilidade dessa metodologia foi investigada para a obtenção de guaianolidos com fusão lactônica cis na posição C6-C7 e para sintetizar um precursor para estudo posterior da transformação biomimética de guaianolidos em pseudoguaianolidos.
\end{abstract}

The $\alpha$-methylene- $\gamma$-lactones 4(15)-dihydroeremanthine (8), 4(15),9(10)-tetrahydroeremanthine (9), isoeremanthine (10), allylic acetate $\Delta^{1,10}(\mathbf{1 1}), 1(\mathrm{R}), 10(\mathrm{R})$-dihydromicheliolide (12) and $4 \alpha$ hydroxy allylic acetate $\Delta^{1,10}(\mathbf{1 3})$ were synthesized from the abundant natural product eremanthine (1). These substances were submitted to hydrolysis reaction with aqueous $\mathrm{KOH}$ and the carboxylic salts of these lactones had their hydroxy groups activated at the C-6 position by formation of respective mesylates $\left(\mathrm{MsCl}, \mathrm{Et}_{3} \mathrm{~N}\right.$, THF or DMSO) which underwent further displacement by carboxylate group. The utility of this methodology was investigated in order to obtain guaianolides with cis lactonic fusion at the C6-C7 position and to synthesize a precursor for posterior study of the biomimetic transformation of guaianolides into pseudoguaianolides.

Keywords: eremanthine, inversion of configuration, molecular conformation

\section{Introduction}

Sesquiterpene lactones, with their several skeletons, constitute a great class of natural products generally found in Compositae family. Among these sesquiterpenolides, two groups of substances have received considerable attention in what refers to isolation and synthesis, due to their biological properties and varied structural patterns. These substances are the guaianolides and their biogenetical derivatives, the pseudoguaianolides. ${ }^{1}$

Guaianolides have the skeleton of bicyclo[5.3.0]decane, characteristic of sesquiterpenes denominated guaianes, to which was inserted at positions C- 6 and C-7 or C-7 and $\mathrm{C}-8$ a $\gamma$-lactonic ring containing in $\mathrm{C}-11$ a methyl group or a vinylic methylene and at positions $\mathrm{C}-4$ and $\mathrm{C}-10$ methyl groups or vinylic methylenes. As examples of guaianolides we can cite eremanthine (1), a schistosomicidal substance isolated

*e-mail: alvesjcf@yahoo.com.br

$\dagger$ Deceased in 1993 from Brazilian compositae Eremanthus elaeagnus and Vanillosmopsis erythropappa, ${ }^{2}$ and gaillardin (2) ${ }^{3}$ (Figure 1).

Pseudoguaianolides also have the skeleton of bicyclo[5.3.0]decane to which is associated a $\gamma$-lactonic ring. They usually have a $\beta$-methyl group at $\mathrm{C}-5$ position and are classified as ambrosanolides and helenanolides according to the stereochemistry of methyl group at $\mathrm{C}-10$; in other words, ambrosanolides have $\beta$-methyl and helenanolides an $\alpha$-methyl in this position. Damsin $(\mathbf{3})^{4}$ and carpesiolin $(\mathbf{4})^{5}$ are ambrosanolides and helenalin $(\mathbf{5})^{6}$ and aromatin $(\mathbf{6})^{7}$ are helenanolides examples (Figure 2).

Continuing the research program about chemical transformations of eremanthine (1), whose initial results were published in a recent article, ${ }^{8}$ in this paper we report the syntheses of 4(15)-dihydroeremanthine (8), 4(15),9(10)tetrahydroeremanthine (9), isoeremanthine (10), allylic acetate $\Delta^{1,10}(\mathbf{1 1}), 1(\mathrm{R}), 10(\mathrm{R})$-dihydromicheliolide (12) and $4 \alpha$-hydroxy allylic acetate $\Delta^{1,10}(\mathbf{1 3})$ and posterior reaction of lactonic fusion inversion on these derivatives (Figure 3). It was evaluated in this study of lactonic inversion on 


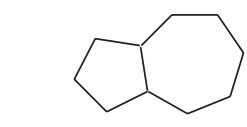

Bicyclo[5.3.0]decane

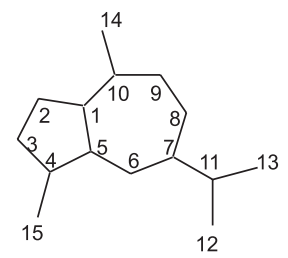

Guaiane<smiles>CC1CCC2C(C)C(=O)OC2C1C</smiles>

Guaianolide

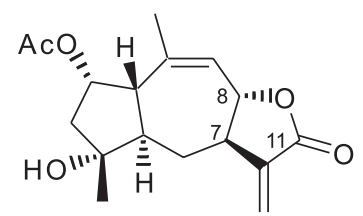

Gaillardin (2)<smiles>CC1CC2OC(=O)C(C)[C@H]2CC2C(C)CCC12</smiles>

Eremanthine (1)

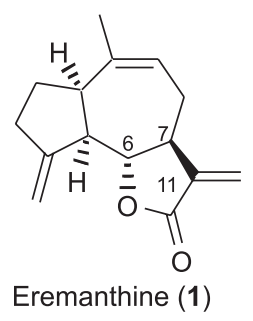

Figure 1. Guaianolides.<smiles>C1CCC2CCCC2CC1</smiles>

Bicyclo[5.3.0]decane

Ambrosanolides

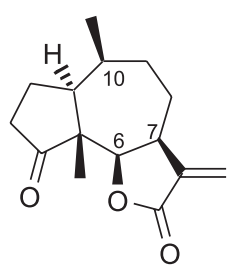

Damsin (3)

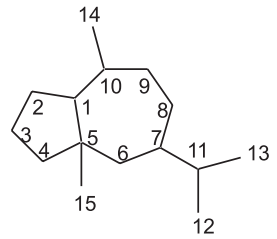

Pseudoguaiane<smiles>CC1CCC2C(C)C3CCCC3(C)[C@H]2OC1=O</smiles>

Pseudoguaianolide

Helenanolides<smiles>C=C1C(=O)O[C@H]2C[C@H](C)[C@H]3C=CC(=O)[C@]3(C)[C@H]12</smiles>

Helenalin (5)<smiles>CC1[C]2CC3(C)CCCC3C(C)C[C@@H]2OC1=O</smiles>

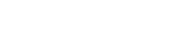

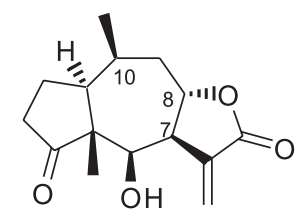

Carpesiolin (4)

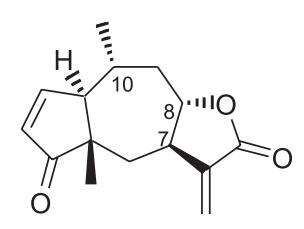

Aromatin (6)

Figure 2. Pseudoguaianolides.

eremanthine derivatives, the viability of obtaining guaianolides with cis lactonic fusion at the $\mathrm{C} 6-\mathrm{C} 7$ position and substances containing the structural requirements for subsequent study of biomimetic transformation of guaianolides into pseudoguaianolides.

\section{Strategies for the syntheses of eremanthine derivatives}

Previous studies on the lactonic fusion inversion of eremanthine (1) led to the synthesis of 6-epi-eremanthine (7) (see Figure 3) that was shown unstable. Such instability was attributed to conformational effects of hydroazulene system $^{9}$ that resulted in a high tension at the lactonic ring, evidenced through its infrared spectral data. ${ }^{10,11}$ Due to the instability of synthesized 6-epi-eremanthine, it was intended to evaluate the reactivity of eremanthine derivatives in the reaction of lactonic fusion inversion, in order to obtain more stable epimers.

For this study of stereochemical inversion on the C-6 position, it was idealized to synthesize substances derived from 1 differing in the unsaturation degree as well as in the positions of double bonds at the hydroazulene system. Such procedure would result in the formation of substances, that we denominated as models, with different conformations and steric interactions among their functional groups, due to the flexibility of the system in study. Therefore, the models 8-13 (Figure 3) were selected to be submitted to conditions of lactonic fusion inversion.

The synthesis of substance $\mathbf{8}$ was idealized through the chemoselective reduction of double bond C4-C15 at the eremanthine methoxy derivative (14), with hydrogen and catalyst, followed by restoration of $\alpha$-methylene- $\gamma$ - 
lactone for methanol elimination. ${ }^{12}$ The synthesis of substance 9 was planned in the same conditions employed in the conversion of $\mathbf{1 4}$ in $\mathbf{8}$ using, in this case, more drastic conditions of hydrogen pressure during the stage of catalytic hydrogenation, since trisubstituted double bond (C9-C10) is less reactive than disubstituted double bond (C4-C15). Isoeremanthine (10) was previously synthesized from isomerization of double bond $\mathrm{C} 4-\mathrm{C} 15$ of eremanthine (1) to $\mathrm{C} 3-\mathrm{C} 4$ position and it would be obtained by the same procedure. ${ }^{13}$ For the synthesis of allylic acetate $\mathbf{1 1}$ we planned to obtain it through an elimination step of iodohydrins 18-19, previously described, ${ }^{14}$ by metal in acid medium to generate the respective products $\mathbf{1 6}$ and $\mathbf{1 1} .^{15}$ In the case of allylic alcohol 16, it would be made an additional stage of protection at the hydroxy group in C-9 position through an acetylation reaction for obtention of compound 11. Alternatively, substance $\mathbf{1 1}$ would be obtained starting from iodohydrin $\mathbf{2 0},{ }^{8}$ by the same procedure used in the conversion of $\mathbf{1 8}$ in $\mathbf{1 6}$, followed by stage of methanol elimination commonly used with eremanthine derivatives ${ }^{12}$ and subsequent acetylation of hydroxy group at C-9 position. Substance 12, previously synthesized from diol $\mathbf{2 1},{ }^{8}$ would be obtained by the same procedures. Substance $\mathbf{1 3}$ would be obtained by simple reaction of methanol elimination accomplished on compound 21, previously described, ${ }^{8}$ followed by acetylation of hydroxy group at C-9 position.
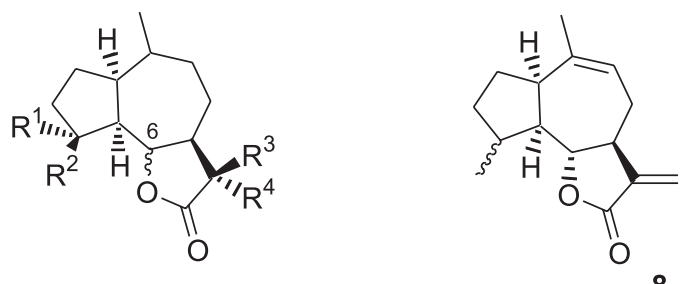

1: $\mathrm{R}^{1}-\mathrm{R}^{2}=\mathrm{R}^{3}-\mathrm{R}^{4}=\mathrm{CH}_{2} ; \Delta^{9,10} ; \mathrm{C}_{6}-\mathrm{H} \beta$

7: $\mathrm{R}^{1}-\mathrm{R}^{2}=\mathrm{R}^{3}-\mathrm{R}^{4}=\mathrm{CH}_{2} ; \Delta^{9,10} ; \mathrm{C}_{6}-\mathrm{H \alpha}$

14: $\mathrm{R}^{1}-\mathrm{R}^{2}=\mathrm{CH}_{2} ; \mathrm{R}^{3}=\mathrm{H} ; \mathrm{R}^{4}=\mathrm{CH}_{2} \mathrm{OMe} ; \Delta^{9,10} ; \mathrm{C}_{6}-\mathrm{H} \beta$

15: $R^{1}=\mathrm{OCH}_{2}=\mathrm{R}^{2} ; \mathrm{R}^{3}-\mathrm{R}^{4}=\mathrm{CH}_{2} ; 9,10-\alpha$-epoxy; $\mathrm{C}_{6}-\mathrm{H} \beta$

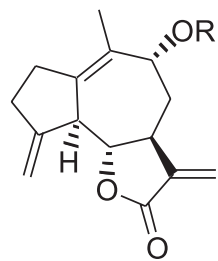

11: $R=A c$

16: $\mathrm{R}=\mathrm{H}$

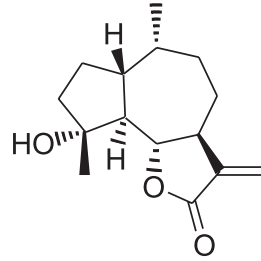

12

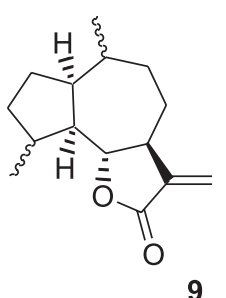

9
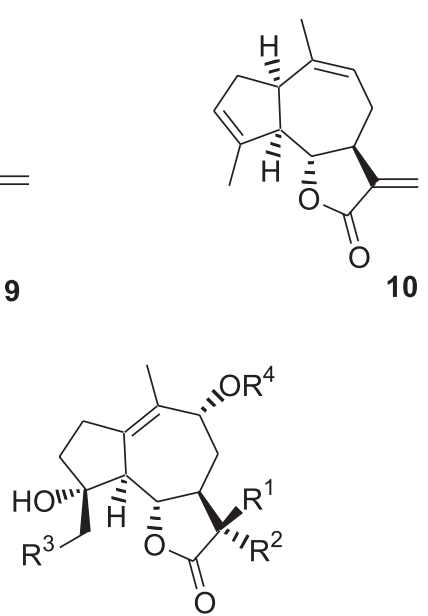

13: $R^{1}-R^{2}=\mathrm{CH}_{2} ; \mathrm{R}^{3}=\mathrm{H} ; \mathrm{R}^{4}=\mathrm{Ac}$

17: $\mathrm{R}^{1}-\mathrm{R}^{2}=\mathrm{CH}_{2} ; \mathrm{R}^{3}=\mathrm{R}^{4}=\mathrm{H}$

18: $R^{1}-R^{2}=C_{2} ; R^{3}=I ; R^{4}=H$

19: $R^{1}-R^{2}=C_{2} ; R^{3}=I ; R^{4}=A C$

20: $R^{1}=R^{4}=H ; R^{2}=\mathrm{CH}_{2} \mathrm{OMe} ; \mathrm{R}^{3}=$ I

21: $R^{1}=R^{3}=R^{4}=H ; R^{2}=\mathrm{CH}_{2} \mathrm{OMe}$

Figure 3. Eremanthine (1) and synthetic derivatives. 


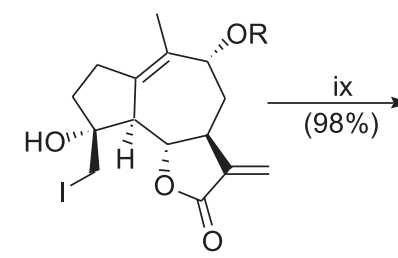<smiles>[R]O[C@H]1C[C@H](C([R])([R])C(=O)O)[C@H](O)[C@@]2(C)C(=C)CCC1=C2C</smiles><smiles>CC(C)(C)C</smiles>

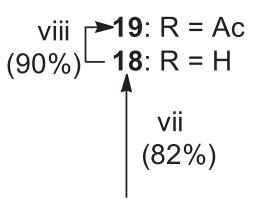<smiles>C=C1C(=O)O[C@H]2[C@H]1CC[C@@H]1OC[C@H](O1)[C@H]2C</smiles>

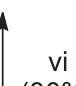
$(80 \%)$<smiles>C=C(C)[C@H]1CC=C(C)[C@@H]2CCC(=C)[C@@H]2[C@H]1OC(C)=O</smiles><smiles>C[13CH][13CH]</smiles><smiles>C=C1C(=O)O[C@H]2[C@@H]1CC=C(C)[C@@H]1CC=C(C)[C@H]21</smiles>

$$
\begin{aligned}
& \text { viii 16: } \mathrm{R}^{1}=\mathrm{H} ; \mathrm{R}^{2}-\mathrm{R}^{3}=\mathrm{CH}_{2} \\
& (95 \%) \rightarrow 11: R^{1}=A c ; R^{2}-R^{3}=\mathrm{CH}_{2} \\
& \text { 25: } R^{1}=R^{2}=H ; R^{3}=\mathrm{CH}_{2} \mathrm{OMe}
\end{aligned}
$$<smiles>C=C1C(=O)O[C@H]2[C@@H]1CC=C(C)[C@@H]1CC[C@@H](C)[C@H]12</smiles>

4

i-ii $(66 \%)$ ix

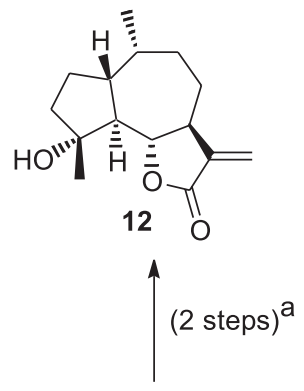<smiles>C=C1CC[C@H]2C(C)=CC[C@H](CCOC)[C@H](C(=O)OC)[C@@H]12</smiles>
14<smiles>C1CC[Bi]C1</smiles><smiles>CCCC[C@@H]1OC(=O)[C@H](COC)[C@@H]2C[C@H](O)C(C)=C3CC[C@](C)(O)[C@H]3[C@@H]12</smiles>
$(81 \%)$<smiles>C=C1C(=O)O[C@H]2[C@@H]1CCC(C)[C@H]1CCC(C)[C@H]12</smiles>

Probable Products:

$\left\{\begin{array}{l}\text { a: } \mathrm{C}_{4}-H \beta ; C_{10}-H \beta \\ \text { b: } C_{4}-H \beta ; C_{10}-H \alpha \\ \text { c: } C_{4}-H \alpha ; C_{10}-H \beta\end{array}\right\}$

$9 a: 9 b: 9 c=3: 2: 5$ ix
$(91 \%)$

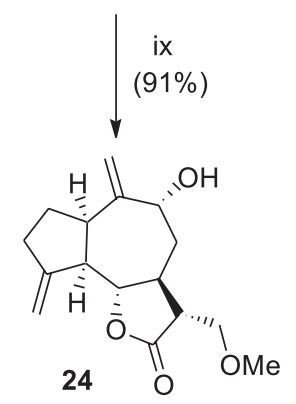<smiles>COC[C@H]1C(=O)O[C@H]2[C@@H]3C(=C(C)[C@@H](O)C[C@H]12)CC[C@]3(O)CI</smiles>

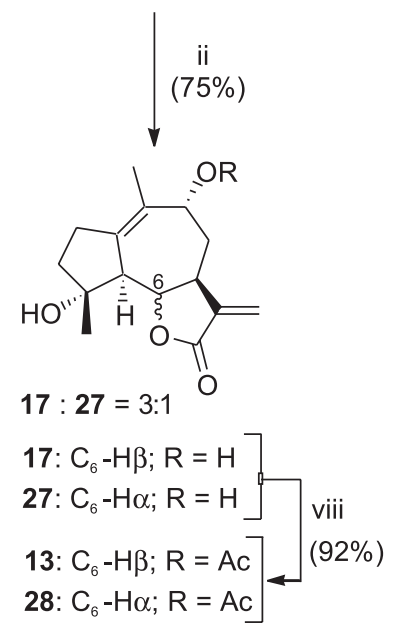

Scheme 1. Reagents and conditions: $i) \mathrm{H}_{2}(40 \mathrm{psi}), 10 \% \mathrm{Pd}-\mathrm{C}\left(0.05\right.$ equiv.), EtOH (r. t. - 1 h); ii) $4 \mathrm{~mol} \mathrm{~L}^{-1} \mathrm{NaOH}\left(5.5\right.$ equiv.), DMF (reflux - 2 h); iii) $\mathrm{H}_{2}(60$ psi), $10 \%$ Pd-C (0.1 equiv.), EtOH (r. t. - 4 h); iv) $4 \mathrm{~mol} \mathrm{~L}^{-1} \mathrm{NaOH}\left(5.5\right.$ equiv.), DMF (reflux - 6 h); v) $\mathrm{BF}_{3} . \mathrm{OEt}_{2}\left(1.1\right.$ equiv.), benzene (r. t. - 5.5 h); vi) $\mathrm{AcO}_{2} \mathrm{H}$ $/ \mathrm{CHCl}_{3}$ (r. t. - 96 h); vii) KI (1.1 equiv.), $\mathrm{AcOH}$ (15 equiv.), acetone (reflux - 5 h); viii) $\mathrm{Ac}_{2} \mathrm{O} /$ pyridine (r. t. - 2 h); ix) $\mathrm{Zn}$ (15 equiv.), AcOH (5 equiv.), EtOH (reflux - $30 \mathrm{~min}$.). ${ }^{\text {a }}$ See reference 8.

respective integrals relative to the signals of hydrogens C6-H at $\delta 4.17(\mathrm{t}, J 10.5 \mathrm{~Hz}), 4.02(\mathrm{dd}, J 9.3$ and 10.2 $\mathrm{Hz})$ and $3.81(\mathrm{t}, J 9.9 \mathrm{~Hz})$. The probable products obtained in these reactions are shown in Scheme 2. As we had observed before in the chemoselective hydrogenation stage of double bond $\mathrm{C} 4-\mathrm{C} 15$ on the eremanthine methoxy derivative (14), it was obtained a 1:1 mixture identified by ${ }^{1} \mathrm{H}$ NMR as epimers $22 \mathrm{a}$ and 22b (Scheme 2). When this mixture, generated in situ, is submitted to subsequent stage of catalytic hydrogenation for reduction of trisubstituted double bond C9-C10, we expect to obtain the 4 diastereoisomers (23ad) shown in Scheme 2. However, it was observed at the ${ }^{1} \mathrm{H}$ NMR spectrum of final product, after stage of methanol elimination, the signals relative to a mixture of only 3 substances. From the calculations of steric 


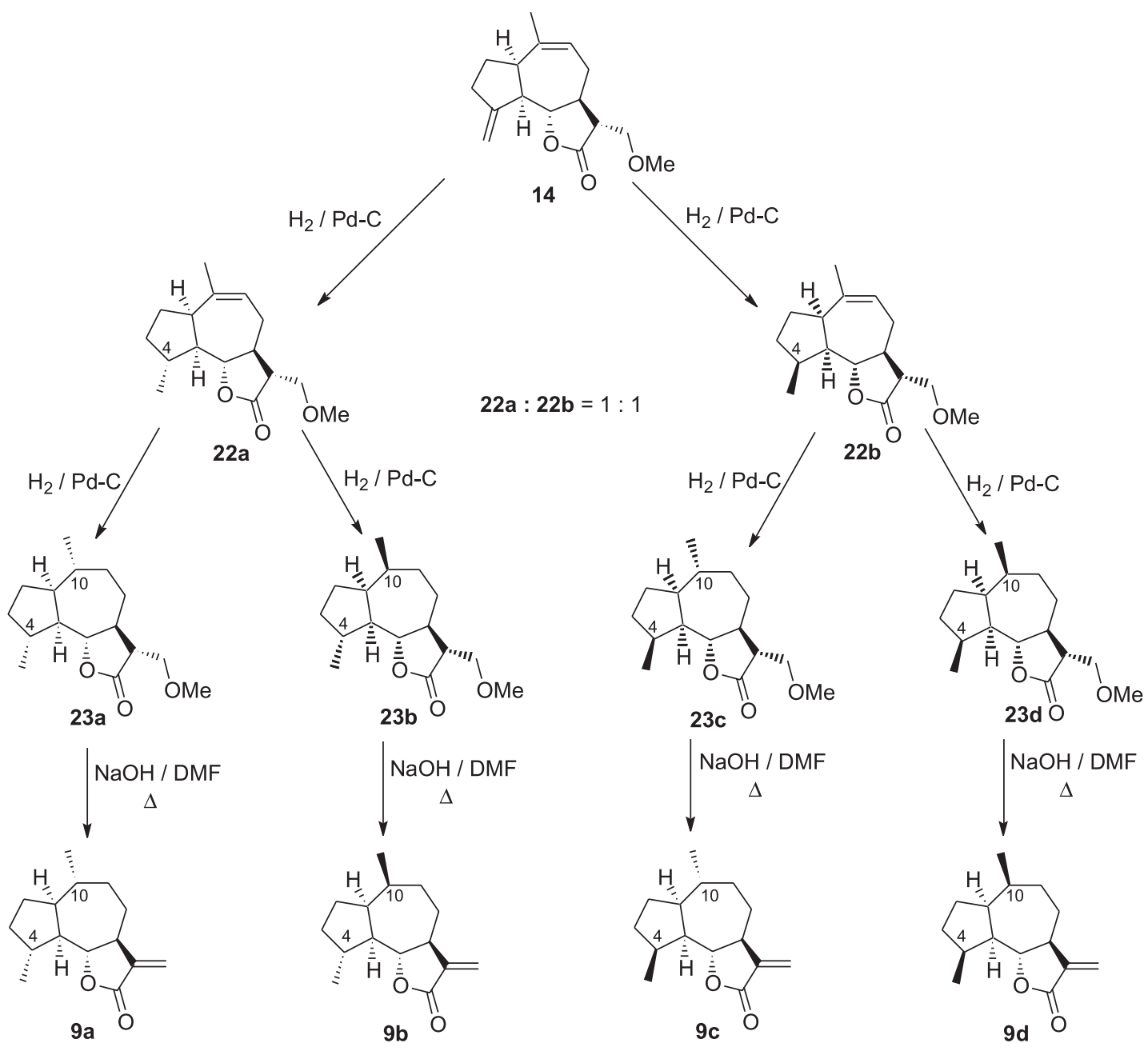

Probable Products: 9a : 9b : 9c $=3: 2: 5$

Scheme 2. Diastereoisomers of model 9.

energies (Table 1), by using MM2 program, ${ }^{16}$ for the probable products (23a-d) obtained after stage of catalytic hydrogenation, we can deduce that the products of this reaction in crescent order of steric energy are the substances 23a-c, that submitted to subsequent stage of methanol elimination give as final products the respective diastereoisomers 9a-c. According to proportion of the three products verified at the ${ }^{1} \mathrm{H}$ NMR spectrum, we can do the following suppositions: as the substances 22a and 22b are generated in same amounts and being considered that formation of compound $\mathbf{2 3 d}$ is disfavored due to steric effects of two bulky methyl groups both in axial $\beta$-position (C14-H and $\mathrm{C} 15-\mathrm{H})$, we can conclude that compound 22b just generates a diastereoisomer, the compound 23c (50\% of the mixture). Compound 22a, for its time, will be responsible for the formation of the other $50 \%$ of the mixture. In this case as product 23a, with the bulky methyl groups $\mathrm{C} 14-\mathrm{H}$ and $\mathrm{C} 15-\mathrm{H}$ in equatorial $\alpha$-position, presents less steric interactions than product 23b that has the bulky methyl group C14$\mathrm{H}$ in axial $\beta$-position and $\mathrm{C} 15-\mathrm{H}$ in equatorial $\alpha$-position, we can expect that 23a are in a larger proportion in the mixture than compound 23b (30\% versus 20\%). These substances when are submitted to stage of methanol elimination give their respective $\alpha$-methylene- $\gamma$-lactones 9c, $9 \mathbf{a}$ and $9 \mathbf{b}$ in a respective proportion of 5:3:2.

For the synthesis of model 10, previously described, ${ }^{13}$ we used conditions $\mathbf{v}$ (Scheme 1). After the time of

Table 1. Steric energies for diastereoisomers 23a-d

\begin{tabular}{lc}
\hline Substances & $\begin{array}{c}\text { Steric Energies } \\
\left(\mathrm{kcal} \mathrm{mol}^{-1}\right)\end{array}$ \\
\hline 23a & 39.144 \\
23b & 39.404 \\
23c & 40.289 \\
23d & 40.970 \\
\hline
\end{tabular}


reaction, a product was isolated and then identified as isoeremanthine (10) by spectroscopy methods. This substance was obtained with high purity, evidenced at the TLC and at their NMR spectra not needing, therefore, of additional purification.

For the synthesis of model 11, previously described, ${ }^{15}$ we employed conditions vi-ix as outlined in Scheme 1. Epoxidation of eremanthine (1) with diluted solution of peracetic acid in chloroform, in conditions vi, generated a product identified as diepoxide $\mathbf{1 5}$. This substance was previously obtained in the same conditions described in Scheme 1 using dichloromethane as the solvent of reaction. ${ }^{17}$ Opening of oxiranic rings of crude product $\mathbf{1 5}$, in acid medium, with equimolar amount of $\mathrm{KI}$ and reflux of acetone (step vii) generated a product that was purified by column cromatography and then identified as iodohydrin 18. Acetylation of substance $\mathbf{1 8}$ at the conditions viii yielded acetate 19. When the substances 18 and 19 were submitted to elimination conditions by metal in acid medium (step ix) it was obtained the respective trienes $\mathbf{1 6}$ and $\mathbf{1 1}$ in almost quantitative yield. These substances were obtained with high purity evidenced at the TLC and at their NMR spectra no needing, therefore, of additional purification. Soon afterwards the hydroxy group at C-9 position of compound $\mathbf{1 6}$ was protected to give allylic acetate $\mathbf{1 1}$ (step viii). This protection stage of allylic alcohol $\mathbf{1 6}$ was accomplished in order to avoid elimination reaction when exposed to $\mathrm{MsCl} / \mathrm{Et}_{3} \mathrm{~N}$ during step of lactonic inversion, since previous attempts of obtaining the mesylate at C-9 position derived from allylic alcohol $\mathbf{2 0}$, gave elimination products with formation of conjugate dienes. ${ }^{18}$ When this same elimination reaction by metal in acid medium (step ix) was accomplished on iodohydrin $\mathbf{2 0}$, for our surprise we obtained substance $\mathbf{2 4}$ instead of the expected product $\mathbf{2 5}$. After analysis of three-dimensional structures of the molecules involved in these processes of chemical transformations, by using MM2 program, ${ }^{16}$ we verified that substances $\mathbf{2 5}$ and $\mathbf{1 6}$ have different conformations at the hydroazulene system (Scheme 3).

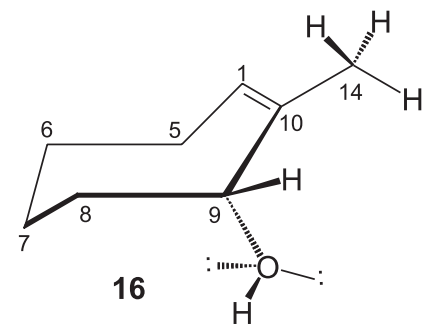

Cycloheptene ring, that commands the geometry of hydroazulene system, is in the chair form at substance 16, with a plane of symmetry passing through the $\mathrm{C}-7$ position $\left(\mathrm{C}_{7}\right)$ while substance $\mathbf{2 5}$ has the seven-membered ring in twist-boat conformation with a pseudo- $\mathrm{C}_{2}$ axis passing through the $\mathrm{C}-8$ position $\left(\mathrm{TB}_{8}\right) .{ }^{9}$ Conformations of the seven-membered ring of substances $\mathbf{1 6}$ and 25, obtained in the MM2 program $^{16}$ are shown at the Figure 4.

Starting from these observations, we concluded that substance $\mathbf{2 5}$ is initially generated as expected and then it should react with zinc species $(\mathrm{I}-\mathrm{Zn}-\mathrm{OH})^{11}$ obtained as subproducts of iodohydrin elimination, to give allylic alcohol 24. In the case of allylic alcohol 16, the subsequent isomerization reaction of double bond $\mathrm{C} 1$ C10 to $\mathrm{C} 10-\mathrm{C} 14$ position, catalysed by $\mathrm{I}-\mathrm{Zn}-\mathrm{OH}$, should not occurs due to probable steric effects of conformation at this molecule that do not favor complexation of I-Zn$\mathrm{OH}$ with the oxygen of hydroxy group at C-9 position and $\mathrm{C}-10 \mathrm{sp}^{2}$ carbon which concentrates a high electronic density. The free-radical mechanism depicted in Scheme 4 was proposed to reaction of reactive intermediate $\mathbf{2 5}$ with $\mathrm{I}-\mathrm{Zn}-\mathrm{OH}$. In this case, the stereochemistry at $\mathrm{C}-1$ position would be defined by stability of the final product, in other words, the radical $\mathbf{B}$ would react with the radical $\mathbf{H}$ to generate the more stable isomer (24). This kind of zinc species complexation, between two sterically related functional groups, was previously proposed to reactions of iodohydrin $\mathbf{1 8}$ with zinc in acid medium and methanol as the solvent, in the generation of $\mathrm{O}^{6,15}$-cycloguaianes derived from eremanthine. ${ }^{11,14}$ The structure of substance $\mathbf{2 4}$ was confirmed by comparison of its ${ }^{1} \mathrm{H}$ NMR, IR and $\mathrm{R}_{\mathrm{f}}$ data with the ones of this substance, previously obtained by opening of epoxide 9,10 - $\alpha$-epoxy-eremanthine in acid medium, followed by a protection stage of $\alpha$-methylene- $\gamma$-lactone with methanol and sodium carbonate. ${ }^{17}$ Moreover, analysing three-dimensional structures of compounds $\mathbf{2 4}$ and (24)-1-epi, obtained by MM2 program, ${ }^{16}$ we can verify differences at these isomers that would implicate in different values of chemical shifts at the signals of

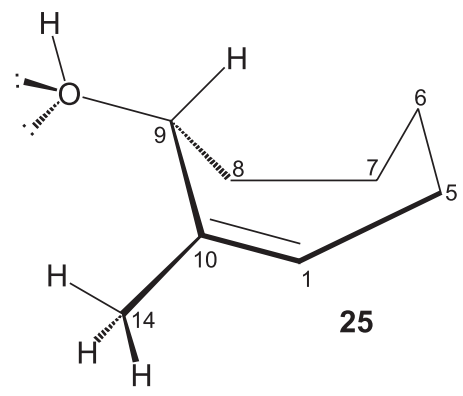

Figure 4. Conformations of the seven-membered ring for the substances $\mathbf{1 6}$ and $\mathbf{2 5 .}$ 
<smiles>COC[C@H]1C[C@@H](O)C(C)=C2CC[C@H](O)[C@]2(CI)[C@@H]1COC(=O)OC</smiles><smiles>C=C1CC2=C(C)[C@H](O)C[C@H](COC)[C@H]2[C@H]1C(=O)O</smiles><smiles>C=C1[C@H]2OC(=O)[C@@H](COC)C[C@@H]2[C@H](COC)C[C@H]1O</smiles>

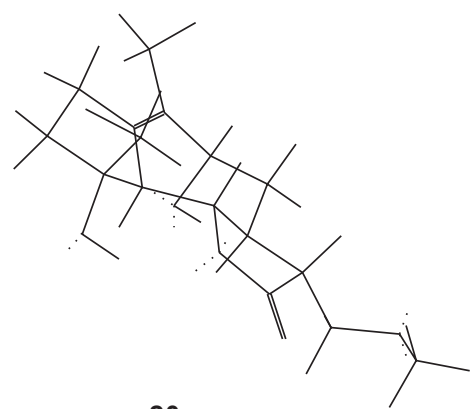

20

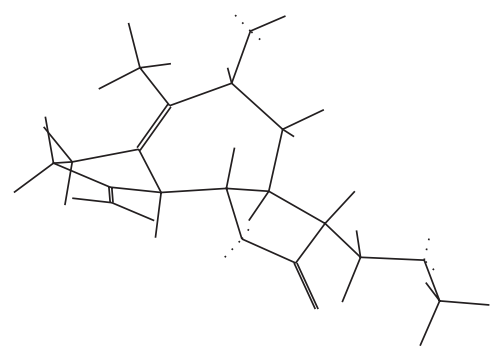

25

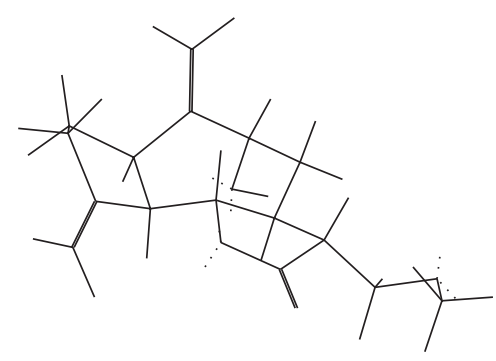

24<smiles>C=C1C(=O)O[C@H]2[C@H]1C[C@H](O)C(C)=C1CC[C@](O)(CI)[C@H]12</smiles><smiles>C=C(C(=O)O)[C@H]1C[C@@H](O)C(C)=C2CCC(=C)[C@H]21</smiles><smiles>C=C1[C@@H](O)C[C@@H]2C(=C)C(=O)O[C@@H]2[C@@H]2C(=C)CC[C@H]12</smiles>

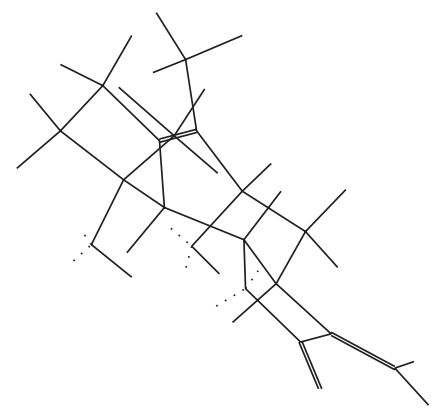

18

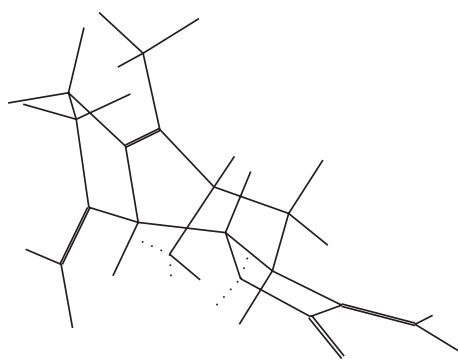

16

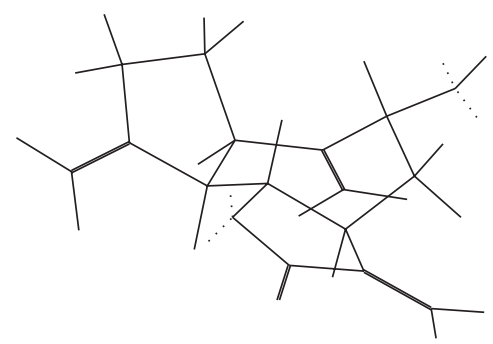

$24 a$

Scheme 3. Reactions of iodohydrins $\mathbf{2 0}$ and $\mathbf{1 8}$ with zinc.

hydrogens of two substances, mainly at the signal of C6$\mathrm{H}$ (see Figure 5). At the isomer $\mathbf{2 4}$ this hydrogen is located at shielding area of double bond $\mathrm{C} 10-\mathrm{C} 14$ located in $\beta$ position. In the isomer (24)-1-epi this shielding effect should be attenuated, due to the change of conformation that puts double bond $\mathrm{C} 10-\mathrm{C} 14$ in $\alpha$-position, opposed to hydrogen $\mathrm{C} 6-\mathrm{H}$. These additional data of molecular modeling contributed to confirm the stereochemistry at C-1 position of substance $\mathbf{2 4}$, since we had obtained the isomer (24)-1-epi its ${ }^{1} \mathrm{H}$ NMR data would be substantially different from those in reference 17.

The initial formation of reactive intermediate $\mathbf{2 5}$ in the generation of product 24, described in Scheme 3, was confirmed in an experiment in which the reaction depicted in Scheme 1 (step ix) was interrupted after 10 minutes from its beginning. The TLC of crude product obtained in this reaction revealed the presence of two substances, with practically identical $R_{\mathrm{f}}$. This mixture was submitted to ${ }^{1} \mathrm{H}$ 


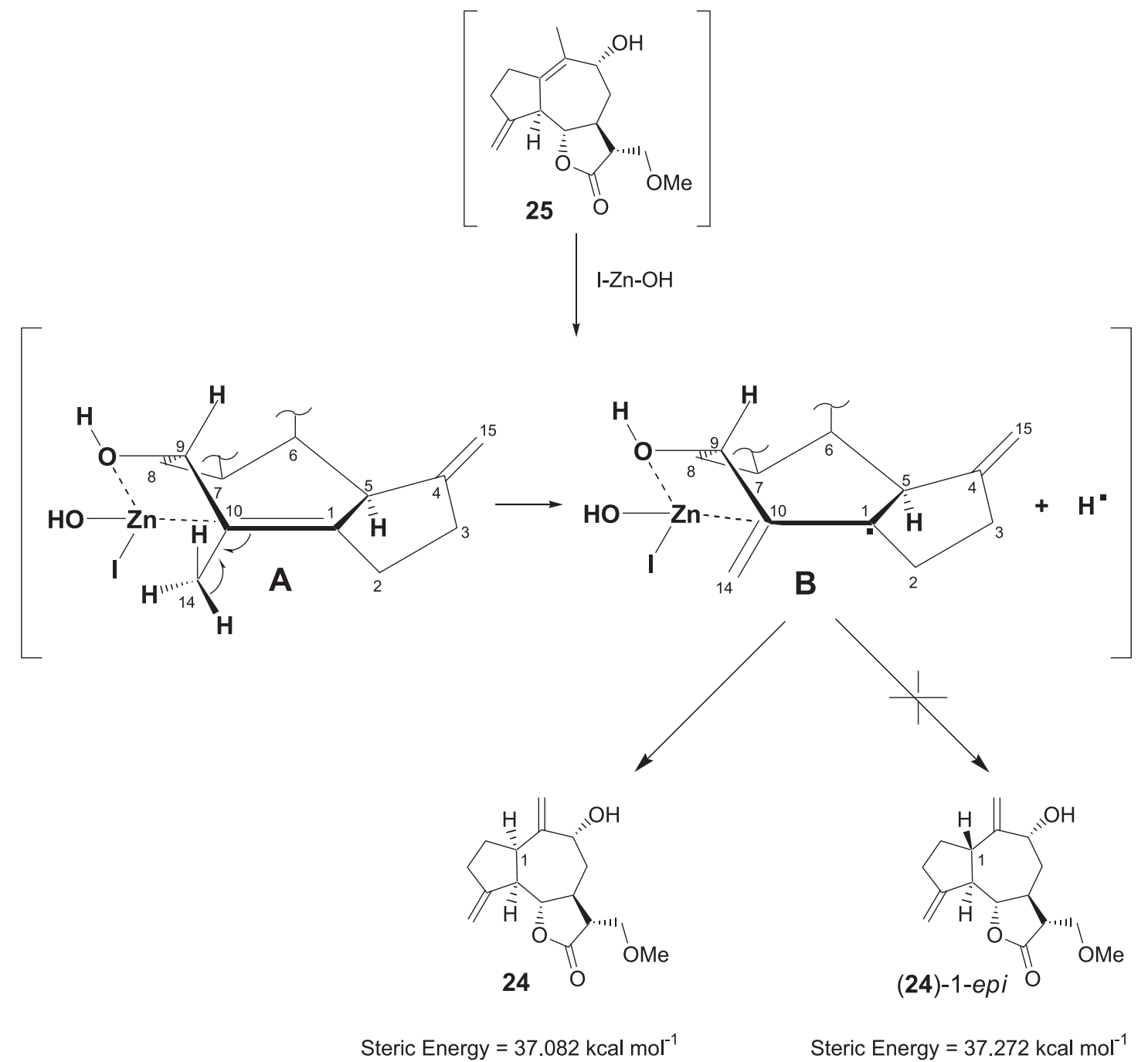

Scheme 4. Speculative mechanism for generation of allylic alcohol $\mathbf{2 4}$.

NMR and it was detected in its spectrum the presence of signals attributed to intermediate $\mathbf{2 5}$ and product $\mathbf{2 4}$ in a respective proportion of 7:4, measured by integrals relative to C9-H signals at $\delta 4.23$ (bd, $J 5.5 \mathrm{~Hz} ; \mathrm{C} 9-\mathrm{H}$ of $\mathbf{2 5}$ ) and 4.48 (t, J $3.5 \mathrm{~Hz}$; C9-H of 24). Signals of the main hydrogens attributed to intermediate $\mathbf{2 5}$ in this spectrum are shown in Table 2.

The synthesis of substance $\mathbf{1 2}$ was described in a recent article about chemical transformations of eremanthine (1). ${ }^{8}$ When diol 21 was submitted to step ii of methanol elimination depicted in Scheme 1, it was obtained a mixture of two products with practically identical $R_{f}$ in a proportion of 3:1, measured by integrals relative to the signals of $\mathrm{C} 13-\mathrm{H}$ of the two products at ${ }^{1} \mathrm{H}$ NMR spectrum. Major product corresponded to diol $\mathbf{1 7}$ previously described $^{11}$ and minor product was later characterized as epimer 27, for occasion of the lactonic inversion reaction of substance $\mathbf{1 7}$ protected in the form of its allylic acetate
13, by comparison of ${ }^{1} \mathrm{H}$ NMR spectra obtained by the two procedures. Soon afterwards the mixture of epimers $\mathbf{1 7}$ and $\mathbf{2 7}$ was submitted to protection stage viii (Scheme 1) of hydroxy groups at C-9 position. The major product of this reaction was separated by column chromatography and then identified as allylic acetate $\mathbf{1 3}$ for spectroscopy

Table 2. Selected chemical shifts for the hydrogens of intermediate $\mathbf{2 5}$ $\left({ }^{1} \mathrm{H}\right.$ NMR $)$

\begin{tabular}{|c|c|}
\hline Hydrogens & $\delta$ (Multiplicity, $J / \mathrm{Hz})^{\mathrm{a}}$ \\
\hline $\mathrm{H}_{\mathrm{a}}-15$ & 5.11 (bs) \\
\hline $\mathrm{H}_{\mathrm{b}}-15$ & $5.03(\mathrm{bs})$ \\
\hline $\mathrm{H}-9$ & $4.23(\mathrm{bd}, 5.5)$ \\
\hline H-6 & $3.68(\mathrm{~m})$ \\
\hline $\mathrm{H}-13$ & $3.64(\mathrm{~m})$ \\
\hline $\mathrm{H}-16$ & $3.33(\mathrm{~s})$ \\
\hline $\mathrm{H}-14$ & 1.79 (bs) \\
\hline
\end{tabular}

${ }^{a}$ Assignment for the hydrogens of intermediate $\mathbf{2 5}$ was made by comparison with those of allylic alcohol $\mathbf{1 6}$. 

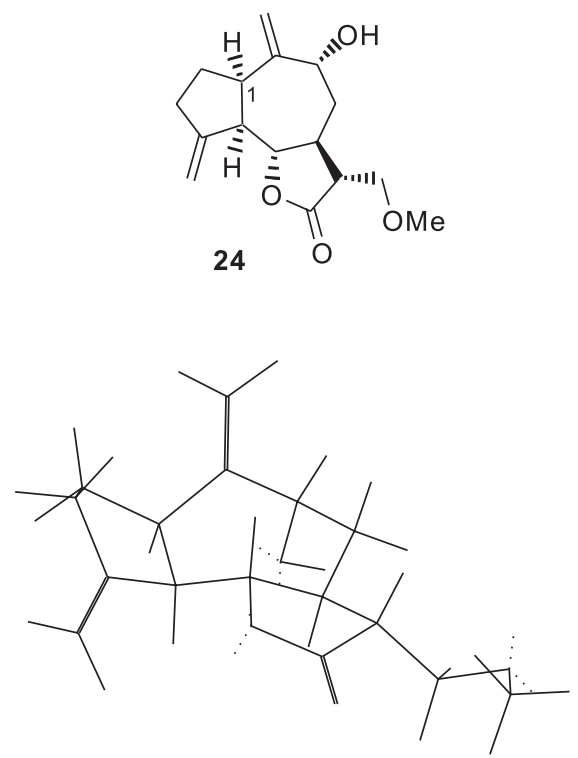

24
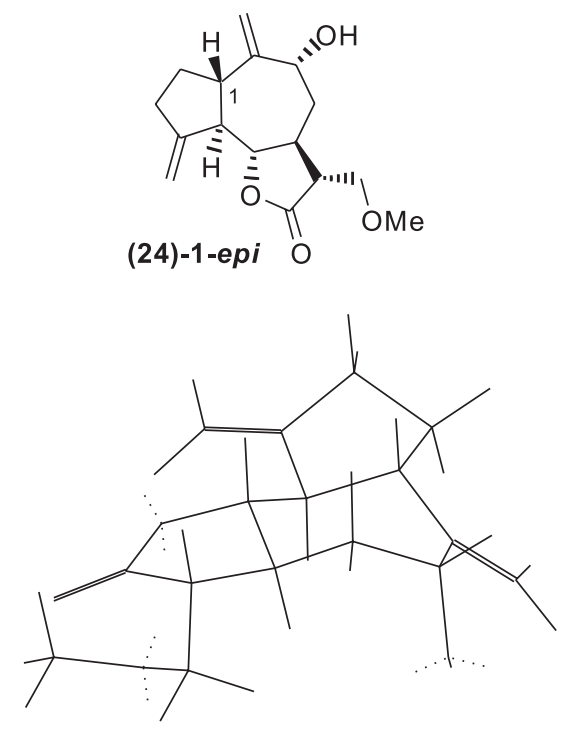

(24)-1-epi

Figure 5. Comparison of the three-dimensional structures of epimers 24 and (24)-1-epi.

methods. This epimeric mixture, obtained at the stage of methanol elimination, was only verified with substance 21 containing double bond at the C1-C10 position of hydroazulene system. This facility to generate product with inversion of configuration at the C-6 position of diol 17 was verified for occasion of the study of lactonic fusion inversion on eremanthine derivatives.

After the preparation of models 8-13 we started the study of the lactonic fusion inversion on these compounds.

\section{Reactions of the lactonic fusion inversion on eremanthine derivatives}

The study of the transformation of eremanthine derivatives with trans lactonic fusion into substances with cis lactonic fusion was accomplished by stereochemical inversion on the alkoxy carbon of the lactonic ring. There are three classic methods to make the configuration inversion on secondary hydroxy groups: the first of them is the traditional method of oxidation-reduction,,${ }^{19}$ in which a hydroxy group is oxidized in a first stage to a ketonic carbonyl group, for in the following stage to be stereoselectively reduced by hydride, to give in the end a hydroxy group with opposite stereochemistry to that of initial secondary alcohol. The inversion of configuration of secondary hydroxy groups can also be made through Mitsunobu's reaction, ${ }^{20}$ in which occurs the activation of hydroxy group in a first stage by formation of an alkoxyphosphonium, for soon afterwards to occur the nucleophylic displacement of this activated leaving group. In the last case, we can cite the method of hydroxy activation by formation of correspondent mesylate, in which the inversion of configuration occurs by nucleophylic displacement of mesylate leaving group. ${ }^{21}$ For the study of stereochemical inversion on alkoxy carbon of the lactones derived from eremanthine (1), we opted for the use of intramolecular displacement of mesylate, since this reaction was previously well described during the stereochemical inversion on the alkoxy carbon of a $\gamma$ lactone with hydroazulene skeleton ${ }^{22}$ and during the synthesis of 6-epi-eremanthine. ${ }^{10,11}$ Attempts to make inversion of configuration on alkoxy carbon of a $\gamma$-lactone with hydroazulene skeleton by displacement of alkoxyphosphonium $^{22}$ or by oxidation-reduction on $\mathrm{C} 6-\mathrm{OH}$ of an eremanthine derivative ${ }^{10,11}$ were unsuccessful.

To study the lactonic fusion inversion on eremanthine derivatives, we used the reaction conditions outlined at Scheme 5 and previously described for the synthesis of 6epi-eremanthine. ${ }^{10,11}$ Therefore, the models 8-13 were submitted to reaction conditions depicted in Scheme 5 , in which at the stage $\mathbf{i}$ starting materials (A) were treated with aqueous solution of potassium hydroxide to generate the correspondent carboxylates $(\mathbf{B})$. At stage ii, we proceeded to evaporation of water and then dryness of residual product in high vacuum. At stage iii dried carboxylates (B) were submitted to treatment with trietylamine and mesyl chloride, conditions wherein sulfene is generated. This reactive species should react with carboxylates in a reversible way to give intermediates such as $\mathbf{C}$, while the reaction of sulfene with the hydroxy group at C-6 should be unreversible to generate intermediates as $\mathbf{D} .{ }^{22}$ Soon 


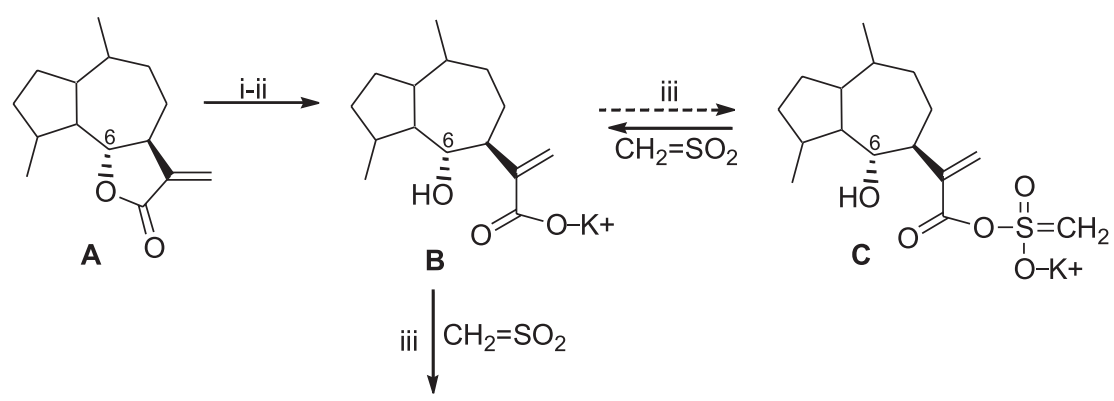

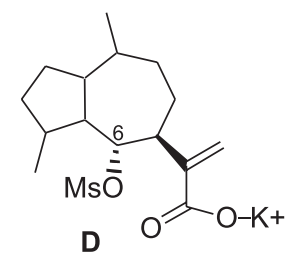

$(\mathrm{SNi})$

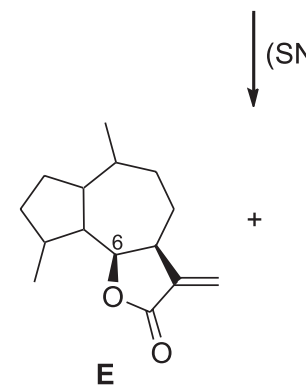

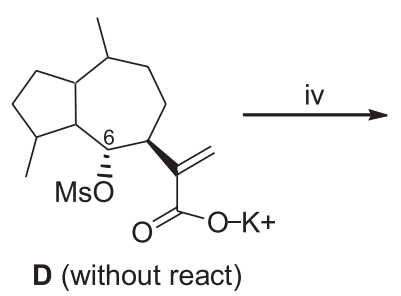
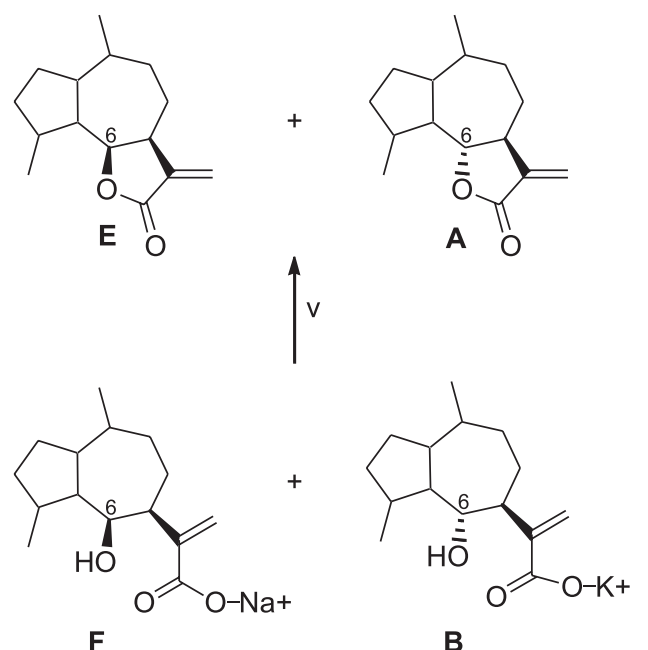

Scheme 5. Reagents and conditions: $i)$ Aqueous $4 \% \mathrm{KOH}$ (4.6 equiv.); ii) dryness; iii) $\mathrm{MsCl}\left(6.0\right.$ equiv.), $\mathrm{Et}_{3} \mathrm{~N}$ ( 7.0 equiv.), Solvent (THF or DMSO) $\left(0{ }^{\circ} \mathrm{C}-1\right.$ h; r. t. $-3 \mathrm{~h}$ ); iv) $0.2 \mathrm{~mol} \mathrm{~L}^{-1} \mathrm{NaOH}\left(3.2\right.$ equiv.; $\left.\left.50{ }^{\circ} \mathrm{C}-1 \mathrm{~h}\right) ; v\right) 10 \%(\mathrm{v} / \mathrm{v}) \mathrm{HCl}, \mathrm{pH} 3$. ${ }^{\mathrm{a}} \mathrm{Time}$ and temperature of hydrolysis reactions are indicated in Table 3.

afterwards, the intramolecular nucleophilic substitution ( $\mathrm{SNi}$ ) should occurs at the intermediates $\mathbf{D}$ to give the compounds $\mathbf{E}$ with cis lactonic fusion, along with any mesylates $\mathbf{D}$ that did not react. At stage iv it was used aqueous solution of sodium hydroxide to hydrolize any mixed anhydrides (C) as well as the mesylates at C-6 (D) that did not suffer nucleophilic displacement by carboxylates. At stage $\mathbf{v}$ aqueous solution of hydrochloric acid was added until $\mathrm{pH} 3$ to convert the carboxylates into respective hydroxy-acids in order to lactonize them giving, in the end, epimeric mixtures at C-6 $(\mathbf{A}+\mathbf{E})$. Crude products of the reactions depicted at Scheme 5 were extracted with organic solvent and then submitted to ${ }^{1} \mathrm{H}$ NMR. The proportion of epimeric products obtained in these reactions was measured by the integrals relative to the signals of $\mathrm{C} 13-\mathrm{H}$. A common characteristic observed at ${ }^{1} \mathrm{H}$ NMR spectra of products with $\mathrm{cis}$ lactonic fusion is related to position of the signals relative to these hydrogens. It was verified at spectra of epimeric mixtures of models 8-13 that all products with cis lactonic fusion presented the signals of $\mathrm{C} 13-\mathrm{H}$ located in higher values of chemical shifts in relation to the ones of substances with trans lactonic fusion. In the cases in which starting materials, with trans lactonic fusion, had double bond at $\mathrm{C} 1-\mathrm{C} 10$ or C9-C10 positions, a deshielding effect was verified at the hydrogen $\mathrm{C} 6-\mathrm{H}$ of their epimers evidenced at the respective ${ }^{1} \mathrm{H}$ NMR spectra. This deshielding effect observed at the C6-H signals of products with cis lactonic fusion was attributed to position change of these hydrogens that passed from the axial position at products with trans lactonic fusion (located at shielding area, on the electronic cloud of double bonds C1-C10 or $\mathrm{C} 9-\mathrm{C} 10)$ to equatorial position, no more on the respective electronic clouds. The cis fusion at the products of lactonic inversion was verified by equatorial-equatorial coupling constants at the $\mathrm{C} 6-\mathrm{H}$ signals. Products of lactonic fusion inversion of models 8-13 are depicted in Table 3 and chemical shifts of the main hydrogens at starting materials and products of inversion reactions are in Table 4.

Initially, some experiments were accomplished with isoeremanthine (10), varying concentrations and times of reaction, in order to verify the ideal conditions for the 
Table 3. Reactions of lactonic fusion inversion of models 8-13

\begin{tabular}{|c|c|c|c|c|c|}
\hline \multirow[t]{2}{*}{ Exp. } & \multirow[t]{2}{*}{ Starting Materials } & \multicolumn{2}{|c|}{ Reactions of opening of the lactonic ring ${ }^{a}$} & \multicolumn{2}{|c|}{ Reactions of lactonic fusion inversion } \\
\hline & & Time (min) & Product & Solvent & $\begin{array}{c}\text { Products } \\
(\% \text { - Proportion })^{\mathrm{b}}\end{array}$ \\
\hline
\end{tabular}

1<smiles>C=C(C(=O)O)C1CC=C(C)C2CCC(C)[C@@H]2[C@@H]1C</smiles>

2<smiles>C=C1C(=O)O[C@H]2C(CC[C@@H](C)[C@@H]3CC[C@H](C)[C@@H]32)C1=O</smiles>

3<smiles>C=C(C)C(=O)OC1CC=C(C)C2CC=C(C)C2[C@@H]1C</smiles>

4<smiles>C=C(C(=O)O)C1C(C)=C2CCC(=C)[C@H]2[C@@H]2C(=C)C(=O)O[C@@H]12</smiles>

5<smiles>C=C(C)C(=O)OC1CCC[C@H]2CCC(C)(O)[C@@H]2[C@H]1O</smiles>

6<smiles>C=C1C(=O)O[C@H]2C(CC1OC(C)=O)C(C)=C1CC[C@](C)(O)[C@H]12</smiles>

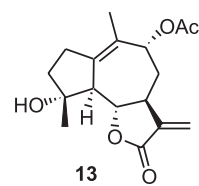

1440

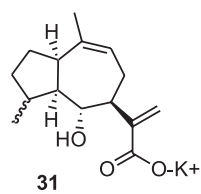

1440

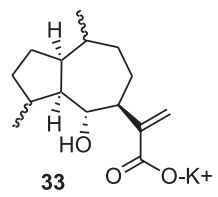

5

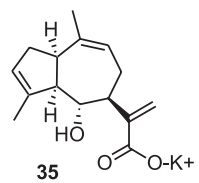

60

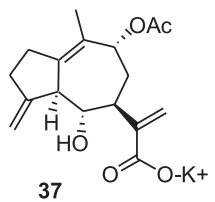

5

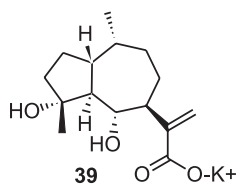

10

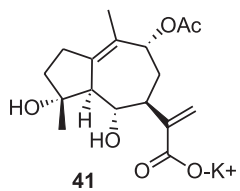

10

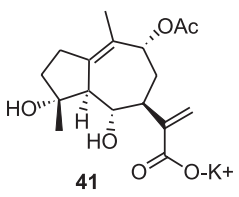

THF

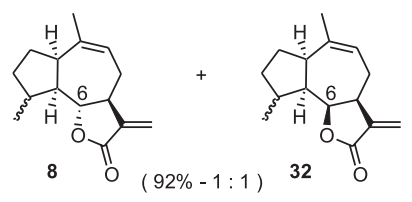

THF

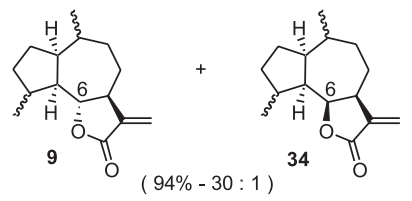

THF

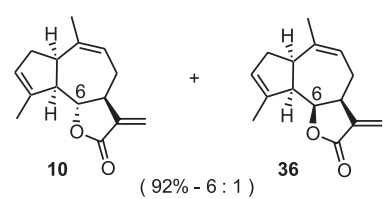

THF

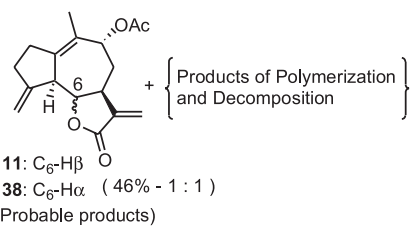

THF

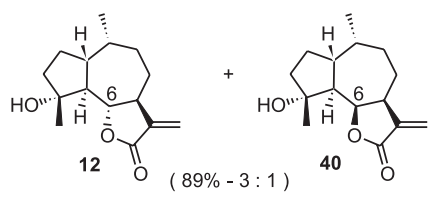

DMSO

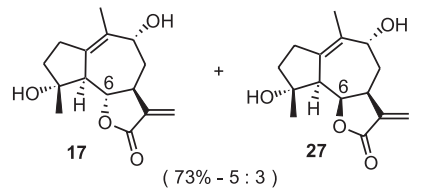

THF

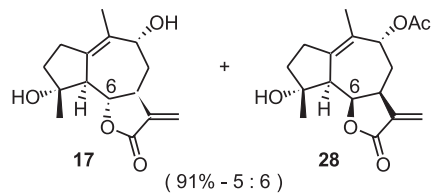

${ }^{a}$ All hydrolysis reactions were performed at room temperature, except in the Exp. 1-2, in which the reaction was initiated at room temperature for $23 \mathrm{~h}$ and then was heated at reflux for more $1 \mathrm{~h}$ to finish it. ${ }^{\mathrm{b}}$ The proportion of products was measured by integrals relative to the signals of $\mathrm{C} 13-\mathrm{H}$ at the ${ }^{1} \mathrm{H}$ NMR spectra of crude products.

reaction of lactonic fusion inversion. The choice of substance $\mathbf{1 0}$ to study the optimization of this reaction was due to the easy access from eremanthine (1) in just a step. In one of the experiments in which the lactonic inversion reaction was executed with $0.1 \mathrm{~mol} \mathrm{~L}^{-1}$ solution, it was obtained 6-epi-isoeremanthine (36) in mixture with a subproduct identified by ${ }^{1} \mathrm{H}$ NMR as the dymer $\mathbf{4 4}$. The proportion of these two substances was 5:1 in favor of 6epi-isoeremanthine (36). Substance 44 resulted from an intermolecular reaction of nucleophilic substitution between two molecules of carboxylate $\mathbf{4 2}$, as speculative mechanism outlined in Scheme 6. The main chemical shifts for the hydrogens of dymer $\mathbf{4 4}$ observed in its ${ }^{1} \mathrm{H}$ NMR spectrum are shown in Table 5. 


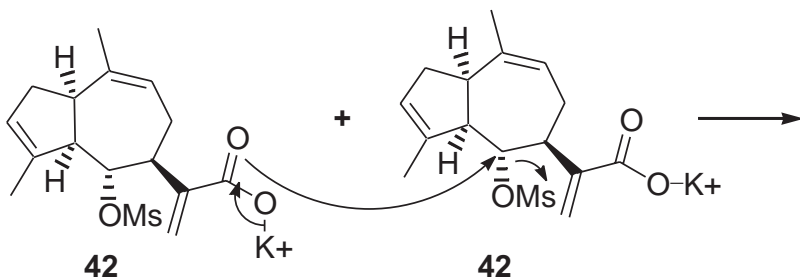

42

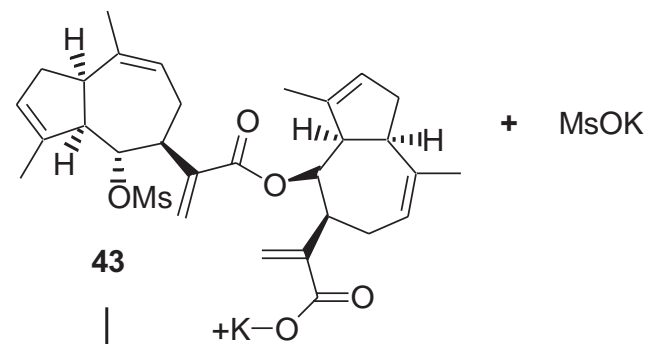

1) $\mathrm{NaOH}-\mathrm{H}_{2} \mathrm{O} / \Delta$

2) $\mathrm{HCl}-\mathrm{H}_{2} \mathrm{O} / \mathrm{pH} 3$

$\downarrow$

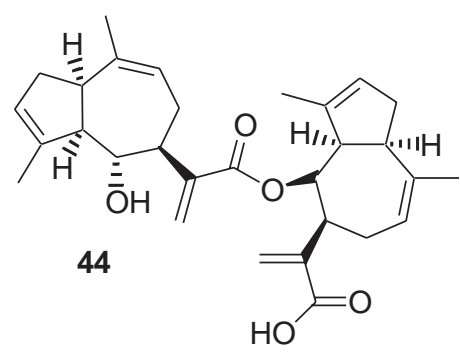

the presence of a $\gamma$-lactone with cis fusion. After experiment to obtain the ${ }^{1} \mathrm{H}$ NMR spectrum, it was made a TLC in which was detected decomposition of the material submitted to NMR, due to the presence of several stains on the plate.

The carboxylic salt $\mathbf{4 1}$ was not much soluble in the solvent THF that we chose to study the reaction of lactonic fusion inversion on the models presented in Table 3. Due to this property we performed the Experiment 6 (Table 3 ), in which the reaction was executed with DMSO. The reduction in the yield of crude product at this reaction was attributed to losses in the partition phase due to the high polarity of the used solvent (DMSO). Moreover, it was verified a reduction in the conversion rate to epimeric product 27. The ${ }^{1} \mathrm{H}$ NMR spectrum of crude product from Experiment 6 was identical to that previously obtained in the stage of methanol elimination on diol 21 (see Scheme 1 - step ii), from where it was confirmed that the subproduct obtained in that reaction was the epimer 27. At the Experiment 7 (Table 3 ) this reaction was performed with THF and we obtained the epimer $\mathbf{2 8}$, with cis lactonic fusion, in a double proportion of that obtained at the Exp. 6. Surprisingly, the acetate protection group stayed intact at the product $28\left[\delta 2.00\left(\mathrm{~s}, 3 \mathrm{H},-\mathrm{OCOCH}_{3}\right)\right.$ and $5.09(\mathrm{~m}$, $1 \mathrm{H}, \mathrm{C} 9-\mathrm{H})-{ }^{1} \mathrm{H} \mathrm{NMR}$ ], suggesting that hydrolysis of this protection group in the solvent THF occurs in a slower rate than the one of the acetate at the substance $\mathbf{1 3}$.

After verification that the configuration inversion on C-6 position of substance $\mathbf{1 7}$ could be done directly, starting from diol $\mathbf{2 1}$ at the stage of methanol elimination, we 
Table 4. Selected chemical shifts for the hydrogens of starting materials and products of the reactions of lactonic fusion inversion at the ${ }^{1} \mathrm{H}$ NMR spectra

\begin{tabular}{|c|c|c|c|c|c|c|}
\hline \multirow[t]{2}{*}{ Exp. } & \multirow{2}{*}{$\begin{array}{l}\text { Starting Materials } \\
\text { and Products }\end{array}$} & \multicolumn{5}{|c|}{ Hydrogens [ $\delta$ (Multiplicity, $J / \mathrm{Hz}$ )] } \\
\hline & & H-6 & H-9 & H-13 & H-14 & H-15 \\
\hline \multirow{4}{*}{1} & 8 & $4.05(\mathrm{~m})$ & $5.55-5.35(\mathrm{~m})$ & $6.20-6.05(\mathrm{~m})$ & 1.78 (bs) & $1.13(\mathrm{~d}, 6.4)$ \\
\hline & & $3.64(\mathrm{~m})$ & & $5.55-5.35(\mathrm{~m})$ & 1.69 (bs) & $0.92(\mathrm{~d}, 6.4)$ \\
\hline & 32 & $4.16(\mathrm{~m})$ & $4.25-4.10(\mathrm{~m})$ & $7.26(\mathrm{~d}, 2.2)$ & - & - \\
\hline & & & & $7.24(\mathrm{~d}, 2.4)$ & & \\
\hline \multirow{10}{*}{2} & 9 & $4.17(\mathrm{t}, 10.5)$ & - & $6.18(\mathrm{~d}, 3.6)$ & & \\
\hline & & $4.02(\mathrm{dd}, 9.3$ and 10.2$)$ & & $6.15(\mathrm{~d}, 3.3)$ & & \\
\hline & & $3.81(\mathrm{t}, 9.9)$ & & $6.13(\mathrm{~d}, 3.5)$ & $0.97(\mathrm{~d}, 7.2)$ & $1.17(\mathrm{~d}, 6.4)$ \\
\hline & & & & & $0.95(\mathrm{~d}, 6.2)$ & $1.16(\mathrm{~d}, 6.2)$ \\
\hline & & & & $5.47(\mathrm{~d}, 3.2)$ & & \\
\hline & & & & $5.43(\mathrm{~d}, 3.1)$ & & \\
\hline & & & & $5.38(\mathrm{~d}, 3.2)$ & & \\
\hline & 34 & $4.85-4.75(\mathrm{~m})$ & - & $6.35-6.31(\mathrm{~m})$ & & \\
\hline & & & & $5.55(\mathrm{~d}, 2.6)$ & - & - \\
\hline & & & & $5.49(\mathrm{~d}, 2.7)$ & & \\
\hline \multirow{4}{*}{3} & & & & $6.18(\mathrm{~d}, 3.4)$ & & \\
\hline & 10 & $4.02(\mathrm{dd}, 8.9$ and 10.7) & $5.43(\mathrm{~m})$ & $5.46(\mathrm{~d}, 3.1)$ & 1.77 (bs) & 1.91 (bs) \\
\hline & 36 & 4.78 (bd, 8.0) & $5.21(\mathrm{~m})$ & $6.24(\mathrm{~d}, 2.1)$ & & \\
\hline & & & & $5.58(\mathrm{~d}, 1.9)$ & $1.63(\mathrm{~d}, 1.3)$ & $1.74(\mathrm{~d}, 1.6)$ \\
\hline \multirow{4}{*}{4} & & & & $6.10(\mathrm{~d}, 3.4)$ & & $5.16(\mathrm{~d}, 1.1)$ \\
\hline & 11 & 3.68 (dd, 9.6 and 10.5) & $5.24(\mathrm{dd}, 1.3$ and 5.5$)$ & $5.34(\mathrm{~d}, 3.1)$ & $1.82(\mathrm{~d}, 1.2)$ & $5.08(\mathrm{~d}, 1.1)$ \\
\hline & & & & $6.30-6.10(\mathrm{~m})$ & & \\
\hline & 38 & $4.19(\mathrm{bd}, 5.5)$ & $5.30-4.80(\mathrm{~m})$ & $5.60-5.35(\mathrm{~m})$ & 1.69 (bs) & $5.30-4.80(\mathrm{~m})$ \\
\hline \multirow{4}{*}{5} & 12 & $4.02(\mathrm{t}, 10.2)$ & - & $6.13(\mathrm{~d}, 3.5)$ & & \\
\hline & & & & $5.41(\mathrm{~d}, 3.2)$ & $0.96(\mathrm{~d}, 7.2)$ & $1.34(\mathrm{~s})$ \\
\hline & 40 & $4.12(\mathrm{~d}, 6.4)$ & - & $6.24(\mathrm{bs})$ & - & - \\
\hline & & & & 5.64 (bs) & & \\
\hline \multirow{4}{*}{6} & 17 & $3.85(\mathrm{dd}, 9.9$ and 10.7$)$ & $4.32(\mathrm{~m})$ & $6.20(\mathrm{~d}, 3.4)$ & & \\
\hline & & & & $5.50(\mathrm{~d}, 3.1)$ & $1.81(\mathrm{~d}, 1.2)$ & $1.27(\mathrm{~s})$ \\
\hline & 27 & 4.78 (bd, 5.4) & $4.24(\mathrm{~m})$ & 6.38 (bs) & & \\
\hline & & & & $5.63(\mathrm{bs})$ & - & - \\
\hline \multirow{4}{*}{7} & 13 & $3.85(\mathrm{dd}, 10.2$ and 10.8$)$ & $5.39(\mathrm{dd}, 2.0$ and 4.7$)$ & $6.18(\mathrm{~d}, 3.3)$ & & \\
\hline & & & & $5.45(\mathrm{~d}, 3.1)$ & 1.72 (bs) & $1.27(\mathrm{~s})$ \\
\hline & 28 & 4.79 (bd, 5.6) & $5.09(\mathrm{~m})$ & 6.37 (bs) & & \\
\hline & & & & $5.62(\mathrm{bs})$ & - & - \\
\hline
\end{tabular}

decided to investigate this reaction with more details. Initially, we planned to substitute DMF commonly employed at the reactions of methanol elimination on eremanthine derivatives, for a polar aprotic solvent of lower ebullition point, the acetonitrile. Such procedure was idealized in order to facilitate the isolation of product since the use of DMF, with high ebullition point, turned more difficult the purification process of the elimination products. The starting material initially used on the methanol elimination with the new solvent $\left(\mathrm{CH}_{3} \mathrm{CN}\right)$ was the methoxy derivative 14, due to the easy access from eremanthine (1) in just a stage. The reaction was executed at the conditions described in Scheme 7. After the time of reaction, crude product was extracted and it was verified by TLC total

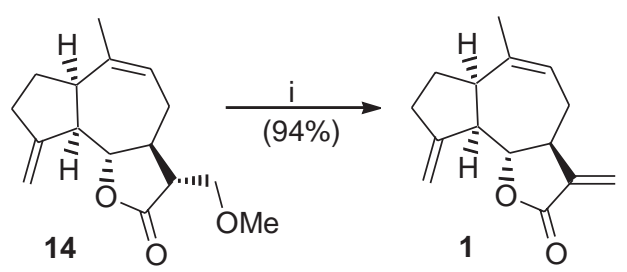

Scheme 7. Reagents and conditions: i) $4 \mathrm{~mol} \mathrm{~L}^{-1} \mathrm{NaOH}$ (5.5 equiv), $\mathrm{CH}_{3} \mathrm{CN}$ (reflux - 5 h).

regeneration of eremanthine (1) with excellent yield and chromatography purity. With this satisfactory result, we performed the elimination reaction with diol 21 (Scheme 8). After the time of reaction, crude product was extracted and then submitted to ${ }^{1} \mathrm{H}$ NMR. The spectrum showed the 
Table 5. Selected chemical shifts for the hydrogens of dymer $\mathbf{4 4}\left({ }^{1} \mathrm{H}\right.$ NMR)

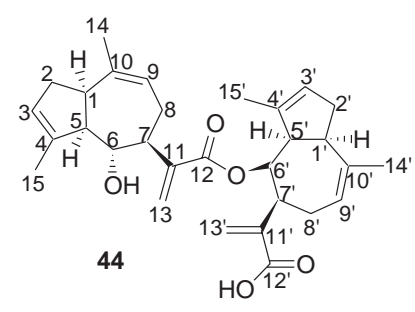

$R_{f}=0.38(15 \%$ EtOAc / hexane)

\begin{tabular}{lc}
\hline Hydrogens & $\delta$ (Multiplicity, $J / \mathrm{Hz})$ \\
\hline $\mathrm{H}_{\mathrm{a}}-13$, & $6.47(\mathrm{dd}, 1.0$ and 2.6$)$ \\
$\mathrm{H}_{\mathrm{a}}-13$ & $6.18(\mathrm{~d}, 3.5)$ \\
$\mathrm{H}_{\mathrm{b}}-13$ & $5.56(\mathrm{dd}, 1.0$ and 2.6$)$ \\
$\mathrm{H}-3$ & $5.51(\mathrm{~m})$ \\
$\mathrm{H}_{\mathrm{b}}-13$ & $5.46(\mathrm{~d}, 3.1)$ \\
$\mathrm{H}-9$ & $5.21(\mathrm{~m})$ \\
$\mathrm{H}-3$ & $4.88(\mathrm{~m})$ \\
$\mathrm{H}-9$ & $4.86(\mathrm{~m})$ \\
$\mathrm{H}-6$ & $4.43(\mathrm{bd}, 10.4)$ \\
$\mathrm{H}-6$ & $4.02(\mathrm{dd}, 8.9$ and 10.2$)$ \\
$\mathrm{H}-15$, & $1.75(\mathrm{bs})$ \\
$\mathrm{H}-15$ & $1.67(\mathrm{bs})$ \\
$\mathrm{H}-14$ & $1.57(\mathrm{bs})$ \\
$\mathrm{H}-14$ & $1.57(\mathrm{bs})$ \\
\hline
\end{tabular}

signals relative to the mixture of epimers $\mathbf{1 7}$ and $\mathbf{2 7}$, in a proportion of 6:5 in favor of epimer $\mathbf{2 7}$ with cis lactonic fusion. This result does suggest the use of acetonitrile as solvent, at the stage of methanol elimination on diol 21 for generation of epimer 27. The use of DMF generated this substance in relation to diol $\mathbf{1 7}$ with trans lactonic fusion in a respective proportion of only 1:3 (see Scheme 1).

\section{Stereochemical considerations}

From the results described in Table 3 for the reactions of lactonic fusion inversion of models 8-13, we can deduce that intramolecular nucleophilic substitution, responsible for configuration inversion on C-6 position of the $\gamma$-lactones in study depends on geometric factors, intrinsic to molecular structure of each substance, that favor the attack of carboxylate to carbon containing the mesylate leaving group. Besides the favorable geometry of reactive substrate to attack by carboxylate, it should also be considered the stability of final product with cis lactonic fusion as well as the conformational interconversions, whose transitions from a particular form to another one generally involve high energies. ${ }^{23}$ Therefore, the low proportions of products with cis lactonic fusion obtained in the Exp. 2, 3 and 5 (Table 3) were attributed to conformational effects in the hydroazulene system that turned the C- 6 position of substrates disfavored to attack by carboxylate, as well as to the changes of conformation in the system, passing from stableer conformations in the substrates to conformers with higher steric energies at products with cis lactonic fusion, according to theoretical calculations obtained with MM2 program. ${ }^{16}$ Due to the few steric interactions observed in the model 11 (Exp. 4 Table 3), the probable successive intermolecular reactions by attack of carboxylate to C-6 position at the reactive intermediate mesylate, resulted in the formation of supposed polymeric subproducts obtained in this reaction. The good conversion rate to product with $c$ is lactonic fusion, obtained by the model 8 (Exp. 1 - Table 3) was attributed to favorable geometry of the carboxylates to attack the C- 6 positions of reactive intermediates containing the mesylate leaving groups, as well as the generation of products (32a-b) with less steric interactions than the substrates $(\mathbf{8 a}-\mathbf{b})$. The best result obtained by the model 13 (Exp. 7 - Table 3) was attributed to favorable geometry of the system for the reaction of lactonic inversion and for not having conformational interconversion in the seven-membered ring, during the transformation process of the substrate (13) into product with cis lactonic fusion (28) (see Table 6).

\section{Conclusions}

The results obtained in this work have demonstrated that allylic acetate $\mathbf{1 3}$ emerged as a promising substance for subsequent preparation of its epimer $\mathbf{2 8}$ in a multigram scale. Compound $\mathbf{2 8}$ was obtained with a good conversion rate starting from substrate $\mathbf{1 3}$ and it was stable in the reaction conditions of lactonic inversion. Moreover we
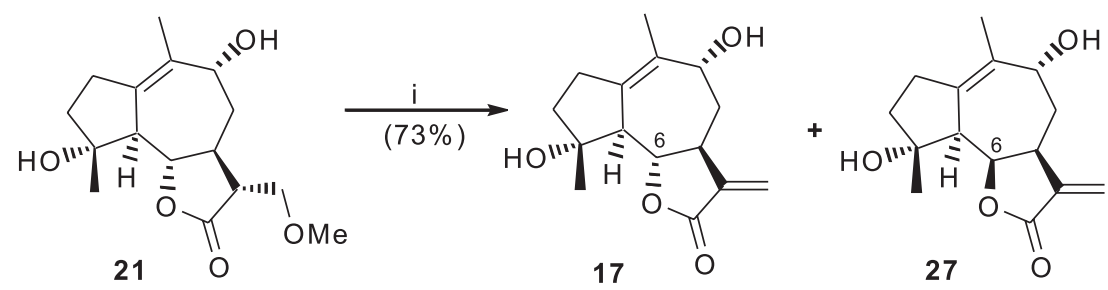

$(5: 6)$

Scheme 8. Reagents and conditions: $i$ ) $4 \mathrm{~mol} \mathrm{~L}^{-1} \mathrm{NaOH}$ (5.5 equiv), $\mathrm{CH}_{3} \mathrm{CN}$ (reflux - $3 \mathrm{~h}$ ). 
Table 6. Conformational diagrams of the seven-membered rings for the hydroazulene system of models $\mathbf{8 - 1 3}$ and their respective products of lactonic fusion inversion

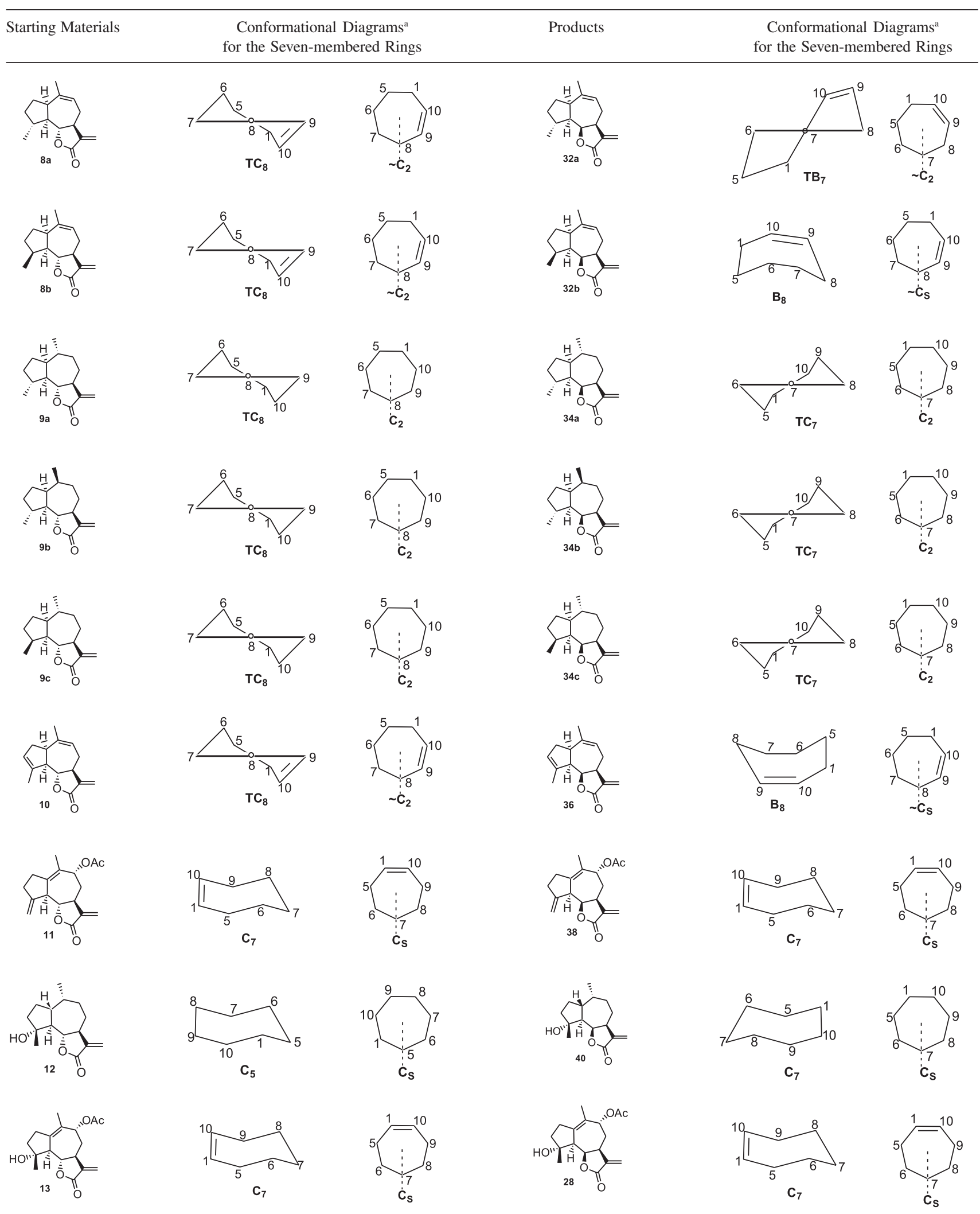

${ }^{a}$ The subscript used in the symbol defining a particular conformation [chair (C), twist-chair (TC), boat (B) and twist-boat (TB)] indicates the atom sectioned by the symmetry element $\left[\mathrm{C}_{2}\right.$-axis $\left(\mathrm{C}_{2}\right)$, pseudo- $\mathrm{C}_{2}$ axis $\left(\sim \mathrm{C}_{2}\right), \mathrm{C}_{\mathrm{S}}$ plane $\left(\mathrm{C}_{\mathrm{S}}\right)$ or pseudo- $\mathrm{C}_{\mathrm{S}}$ plane $\left.\left(\sim \mathrm{C}_{\mathrm{S}}\right)\right]$. 
Table7. Selected torsion angles for the hydroazulene system of models 8-13 and their respective products of lactonic fusion inversion

\begin{tabular}{|c|c|c|c|c|c|c|c|c|c|}
\hline \multirow[t]{2}{*}{ Substances } & \multicolumn{9}{|c|}{ Bonds/Torsion Angles (Degrees) } \\
\hline & O6-C6-C7-C11 & $\mathrm{C} 4-\mathrm{C} 5-\mathrm{C} 1-\mathrm{C} 2$ & $\mathrm{C} 10-\mathrm{C} 1-\mathrm{C} 5-\mathrm{C} 6$ & C9-C10-C1-C5 & C8-C9-C10-C1 & C7-C8-C9-C10 & $\mathrm{C} 6-\mathrm{C} 7-\mathrm{C} 8-\mathrm{C} 9$ & $\mathrm{C} 5-\mathrm{C} 6-\mathrm{C} 7-\mathrm{C} 8$ & $\mathrm{C} 1-\mathrm{C} 5-\mathrm{C} 6-\mathrm{C} 7$ \\
\hline $8 \mathbf{a}$ & -19.653 & 29.181 & 35.910 & -67.890 & 115.557 & -51.952 & -34.736 & 93.719 & -67.002 \\
\hline 32a & 8.900 & 30.314 & 36.275 & 22.140 & -4.364 & -64.627 & 63.447 & 11.379 & -69.646 \\
\hline $8 b$ & -20.421 & 29.270 & 32.400 & -66.570 & 114.277 & 101.215 & -36.745 & 93.167 & -62.197 \\
\hline $32 \mathbf{b}$ & 7.223 & 37.062 & 41.006 & 17.673 & -3.824 & -62.886 & 64.439 & 9.106 & -69.852 \\
\hline $9 a$ & -18.464 & 31.363 & 38.756 & -51.697 & 83.087 & -48.801 & -34.654 & 95.769 & -72.861 \\
\hline $34 a$ & 16.583 & 39.592 & 50.209 & -33.164 & 63.141 & -97.571 & 54.204 & 22.119 & -68.249 \\
\hline $9 b$ & -15.915 & 30.003 & 39.305 & -61.679 & 90.383 & -40.811 & -43.108 & 98.970 & -68.353 \\
\hline $34 b$ & 16.288 & 40.381 & 53.720 & -42.746 & 71.480 & -97.902 & 52.152 & 21.937 & -66.677 \\
\hline 9c & -17.548 & 33.722 & 37.620 & -52.758 & 83.734 & -44.906 & -38.223 & 96.674 & -69.709 \\
\hline $34 c$ & 16.200 & 42.914 & 51.823 & -34.707 & 63.367 & -97.105 & 54.622 & 21.717 & -68.385 \\
\hline 10 & -20.739 & 18.916 & 27.160 & -62.935 & 116.450 & -51.891 & -37.375 & 92.614 & -58.049 \\
\hline 36 & -15.085 & -8.346 & -17.887 & -39.365 & 6.459 & 70.882 & -61.762 & -20.101 & 68.046 \\
\hline 11 & -25.899 & -2.147 & 53.779 & 1.644 & -53.627 & 70.469 & -74.283 & 83.929 & -80.562 \\
\hline 38 & 26.854 & 6.108 & 65.491 & -6.583 & -62.755 & 79.546 & -49.662 & 36.763 & -59.513 \\
\hline 12 & -26.933 & -30.800 & 79.967 & -81.581 & 28.094 & 42.996 & -89.841 & 83.268 & -65.864 \\
\hline 40 & 23.742 & -10.162 & 95.543 & -45.318 & -41.517 & 93.353 & -58.920 & 31.171 & -59.752 \\
\hline 13 & -25.422 & -13.882 & 42.692 & 5.183 & -47.488 & 66.467 & -77.955 & 86.293 & -73.421 \\
\hline 28 & 27.849 & 10.432 & 66.636 & -6.083 & -63.194 & 78.248 & -49.113 & 38.366 & -61.952 \\
\hline 27 & 27.810 & 10.722 & 67.423 & -7.076 & -64.127 & 81.399 & -51.279 & 38.295 & -61.198 \\
\hline
\end{tabular}

verified, from this study, that allylic acetate $\mathbf{2 8}$ can also be easily obtained starting from diol $\mathbf{2 1}$, at the stage of methanol elimination. For this method it was obtained the epimeric allylic alcohols $\mathbf{1 7}$ and $\mathbf{2 7}$ in a proportion of 5:6 in favor of the substance $\mathbf{2 7}$ with cis lactonic fusion, with the use of acetonitrile as the solvent of reaction. Although this mixture of epimeric allylic alcohols has presented separation problems for column chromatography of silica gel, due to the high polarity and proximity of their $\mathrm{R}_{\mathrm{f}}$, their correspondent allylic acetates $\mathbf{1 3}$ and $\mathbf{2 8}$ were easily separated. Allylic acetate $\mathbf{2 8}$, with cis lactonic fusion, has the necessary structural requirements to unchain the rearrangements preconized by the hypothesis of pseudoguaianolides biogenesis, ${ }^{24}$ in other words, $\alpha$-hydroxy group at $\mathrm{C}-4$, oxygen at $\beta$-position at $\mathrm{C}-6$ and a potential cationic center at $\mathrm{C}-1$. These results allow us to idealize the possibility of obtaining the substance $\mathbf{2 8}$ for one of the two epimerization methods developed in this work, for an eventual study of biomimetic transformation of guaianolides into pseudoguaianolides.

\section{Experimental}

Infrared spectra (IR) were recorded on a Perkin-Elmer 1420 spectrophotometer, using either thin films on $\mathrm{NaCl}$ plates (film) or $\mathrm{KBr}$ discs. NMR spectra were recorded on a Bruker AC-200 $\left({ }^{1} \mathrm{H}: 200 \mathrm{MHz}\right.$ and $\left.{ }^{13} \mathrm{C}: 50.3 \mathrm{MHz}\right)$ spectrometer. $\mathrm{CDCl}_{3}$ was used as the solvent and TMS as internal standard. Coupling constants $(J)$ are reported in Hertz (Hz). Multiplicities are indicated as s (singlet), bs (broad singlet), d (doublet), bd (broad doublet), t (triplet), $m$ (multiplet), dd (double doublet). Assignment of the hydrogens was made with base on the Homonuclear Correlation Spectra ${ }^{1} \mathrm{Hx}{ }^{1} \mathrm{H}-\mathrm{COSY}$. Multiplicities of the signals of carbon-13 were obtained using a DEPT sequence. Low resolution mass spectrum of allylic alcohol $\mathbf{1 6}$ was obtained at $70 \mathrm{eV}$, for electrons impact, on a VG AutoSpecQ spectrometer. Thin layer chromatography was performed on aluminium sheets coated with $60 \mathrm{~F}_{254}$ silica. Visualization of the substances on the plates of TLC was accomplished under lamp of ultraviolet light (UV) and/or for contact of the plates with silica gel impregnated with iodine and/or spraying with $2 \% \mathrm{Ce}\left(\mathrm{SO}_{4}\right)_{2}$ in $2 \mathrm{~mol} \mathrm{~L}^{-1} \mathrm{H}_{2} \mathrm{SO}_{4}$ and subsequent heating. Purifications and isolations by column chromatography were performed with silica gel (230-400 mesh). Solvents and reagents were dried and purified by the usual methods. ${ }^{25}$ Hydrogenations were carried out using a Parr apparatus. Melting points were taken on a Kofler apparatus and are uncorrected. The values of steric energies and the three-dimensional structures of substances presented in this paper were obtained by using MM2 and MOPAC programs, minimizing energy to minimun RMS gradient of 0.100 and displaying each iteration. ${ }^{16}$

(11S)-Guai-9-eno-4 $\beta(H)$-13-methoxy-12,6 $\alpha$-lactone (22a)

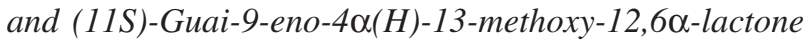
(22b)

Eremanthine methoxy derivative (14) $(0.074 \mathrm{~g}, 0.282$ $\mathrm{mmol}), 10 \%$ Pd-C (0.015 g, $0.0141 \mathrm{mmol})$, ethanol $(7.5 \mathrm{~mL})$ and hydrogen (40 psi) were shaken in a Parr apparatus at 
room temperature for $1 \mathrm{~h}$. The mixture was filtered and concentrated in vacuum. It was obtained a colourless oil $(0.069 \mathrm{~g}, 93 \%)$ characterized as a mixture of diastereoisomers 22a-b. $R_{\mathrm{f}} 0.50$ (25\% EtOAc / hexane). IR (film) $\mathrm{v}_{\max } / \mathrm{cm}^{-1}$ : 2920, 1780, 1765, 1660, 1450, 1380, 1320, 1180, 1100, 1000, 760. ${ }^{1} \mathrm{H} \mathrm{NMR}\left(\mathrm{CDCl}_{3}\right.$, partial assignment): $\delta 5.60-5.30(\mathrm{~m}$, 2H, 2 H-9), 4.02 (dd, J 9.8 and 11.7 Hz, 1H, H-6), 3.75 3.50 (m, 5H, H-6 and $2 \mathrm{H}-13$ ), 3.34 (s, 3H, $-\mathrm{OCH}_{3}$ ), 3.33 (s, $3 \mathrm{H},-\mathrm{OCH}_{3}$ ), $2.70-0.80\{34 \mathrm{H}[1.77$ (bs, H-14), 1.68 (bs, H14), 1.13 (d, J 6.6 Hz, H-15), 0.94 (d, J 6.2 Hz, H-15)]\}.

(11S)-Guaia-4 $\beta(H), 10 \beta(H)$-13-methoxy-12,6 $\alpha$-lactone

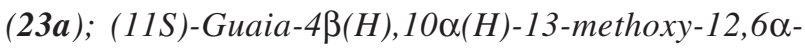
lactone (23b) and (11S)-Guaia-4 $\alpha(H), 10 \beta(H)-13$ methoxy-12,6 $\alpha$-lactone $(23 c)$

Eremanthine methoxy derivative (14) $(0.052 \mathrm{~g}, 0.198$ $\mathrm{mmol}), 10 \% \mathrm{Pd}-\mathrm{C}$ (0.021 g, $0.0198 \mathrm{mmol})$, ethanol (3.0 $\mathrm{mL}$ ) and hydrogen (60 psi) were shaken in a Parr apparatus at room temperature for $4 \mathrm{~h}$. The mixture was filtered and concentrated in vacuum. It was obtained a colourless oil $(0.051 \mathrm{~g}, 96 \%)$ characterized as a mixture of diastereoisomers 23a-c. $\mathrm{R}_{\mathrm{f}} 0.52$ (25\% EtOAc / hexane). IR (film) $v_{\max } / \mathrm{cm}^{-1}: 2920,1775,1460,1180,1100,1000 .{ }^{1} \mathrm{H}$ NMR $\left(\mathrm{CDCl}_{3}\right.$, partial assignment): $\delta 4.20-4.10(\mathrm{~m}, 1 \mathrm{H}, \mathrm{H}-6)$, 4.01 (t, J 9.5 Hz, 1H, H-6), 3.67 (m, 1H, H-6), 3.62 (m, $6 \mathrm{H}, 3 \mathrm{H}-13), 3.33\left(\mathrm{~s}, 9 \mathrm{H}, 3-\mathrm{OCH}_{3}\right), 2.70-0.80\{60 \mathrm{H}$ [1.10 (d, J 6.3 Hz, H-15), 1.09 (d, J 6.4 Hz, H-15), 0.91 (d, J $6.1 \mathrm{~Hz}, \mathrm{H}-14)]\}$.

Guaia-9,11(13)-dieno-12,6 $\alpha$-lactone (8) and Guai-11(13)eno-12,6 $\alpha$-lactone (9)

General procedure for preparation of $\alpha$-methylene- $\gamma$ lactones $\mathbf{8}$ and $\mathbf{9}$

A solution of appropriate methoxy derivative $\mathbf{2 2} / \mathbf{2 3}$ $(0.153 \mathrm{mmol})$ in DMF $(1.0 \mathrm{~mL})$ and aqueous $4 \mathrm{~mol} \mathrm{~L}^{-1}$ $\mathrm{NaOH}(0.2 \mathrm{~mL}, 0.841 \mathrm{mmol})$ was heated at reflux during $2 \mathrm{~h}$ for the reaction with methoxy derivative 22 and $6 \mathrm{~h}$ for the reaction of methoxy derivative 23. After the respective times of reaction, it was allowed to cool at room temperature and aqueous $10 \%(\mathrm{v} / \mathrm{v}) \mathrm{HCl}$ was added dropwise until $\mathrm{pH} 3$. EtOAc $(30 \mathrm{~mL})$ was added and solution was washed with $\mathrm{H}_{2} \mathrm{O}(2 \times 30 \mathrm{~mL})$. The organic layer was separated and aqueous phases were extracted with EtOAc $(2 \times 30 \mathrm{~mL})$. The organic phases were dried with $\mathrm{Na}_{2} \mathrm{SO}_{4}$, filtered and evaporated under reduced pressure. Purification by column chromatography eluted with hexane and $10 \%$ EtOAc / hexane gave:

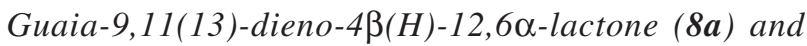

Guaia-9,11(13)-dieno-4 $\alpha(H)$-12,6 $\alpha$-lactone (8b) (0.025 $\mathrm{g}, 71 \%)$ as a colourless oil. $\mathrm{R}_{\mathrm{f}} 0.70$ (25\% EtOAc / hexane). ${ }^{1} \mathrm{H} \mathrm{NMR}\left(\mathrm{CDCl}_{3}\right.$, partial assignment): $\delta 6.20-6.05(\mathrm{~m}$, 2H, $2 \mathrm{H}-13$ ), 5.55 - 5.35 (m, 4H, 2 H-13 and $2 \mathrm{H}-9), 4.05$ (m, 1H, H-6), 3.64 (m, 1H, H-6), $2.80-0.80\{32 \mathrm{H}[1.78$ (bs, H-14), 1.69 (bs, H-14), 1.13 (d, J 6.4 Hz, H-15), 0.92 (d, J $6.4 \mathrm{~Hz}, \mathrm{H}-15)]\}$.

Guai-11(13)-eno-4 $\beta(H), 10 \beta(H)$-12,6 $\alpha$-lactone (9a); Guai11(13)-eno-4 $\beta(H), 10 \alpha(H)-12,6 \alpha$-lactone $(9 \mathrm{~b})$ and Guai11(13)-eno-4 $\alpha(H), 10 \beta(H)$-12,6 $\alpha$-lactone (9c) (0.030 g, $84 \%)$ as a colourless oil. $\mathrm{R}_{\mathrm{f}} 0.76$ (50\% EtOAc / hexane). IR (film) $v_{\text {max }} / \mathrm{cm}^{-1}: 2920,1760,1460,1260,1150,985 .{ }^{1} \mathrm{H}$ $\mathrm{NMR}\left(\mathrm{CDCl}_{3}\right.$, partial assignment): $\delta 6.18(\mathrm{~d}, J 3.6 \mathrm{~Hz}, 1 \mathrm{H}$, H-13), 6.15 (d, J 3.3 Hz, 1H, H-13), 6.13 (d, J 3.5 Hz, 1H, H-13), 5.47 (d, J 3.2 Hz, 1H, H-13), 5.43 (d, J $3.1 \mathrm{~Hz}, 1 \mathrm{H}$, H-13), 5.38 (d, J 3.2 Hz, 1H, H-13), 4.17 (t, J 10.5 Hz, 1H, H-6), 4.02 (dd, J 9.3 and $10.2 \mathrm{~Hz}, 1 \mathrm{H}, \mathrm{H}-6), 3.81$ (t, J 9.9 Hz, 1H, H-6), 2.90 - 2.65 (m, 1H, H-7), 2.65 - 2.45 (m, 1H, H-7), 2.45 - 2.20 (m, 1H, H-7), 2.20 - $0.80\{54 \mathrm{H}[1.17$ (d, $J 6.4 \mathrm{~Hz}, \mathrm{H}-15), 1.16$ (d, J $6.2 \mathrm{~Hz}, \mathrm{H}-15), 0.97$ (d, J 7.2 Hz, H-14), 0.95 (d, J $6.2 \mathrm{~Hz}, \mathrm{H}-14)]\}$.

\section{Isoeremanthine (10)}

A solution of eremanthine (1) $(0.200 \mathrm{~g}, 0.868 \mathrm{mmol})$, dry benzene $(1.6 \mathrm{~mL})$ and $\mathrm{BF}_{3} . \mathrm{OEt}_{2}$ freshly distilled $(0.12$ $\mathrm{mL}, 0.955 \mathrm{mmol}$ ) was stirred at room temperature and nitrogen atmosphere during $5.5 \mathrm{~h}$. The mixture was diluted with $\mathrm{CHCl}_{3}(30 \mathrm{~mL})$ and washed with aqueous $5 \%$ $\mathrm{NaHCO}_{3}(3 \times 25 \mathrm{~mL})$ and $\mathrm{H}_{2} \mathrm{O}(2 \times 25 \mathrm{~mL})$. The organic layer was separated and aqueous phases were extracted with $\mathrm{CHCl}_{3}(1 \times 30 \mathrm{~mL})$. The organic extracts were dried with $\mathrm{Na}_{2} \mathrm{SO}_{4}$, filtered and concentrated in vacuum. It was obtained a yellowish oil $(0.164 \mathrm{~g}, 82 \%)$ identified as isoeremanthine (10). $\mathrm{R}_{\mathrm{f}} 0.76$ (50\% EtOAc / hexane). IR (film) $v_{\max } / \mathrm{cm}^{-1}: 3010,2910,1760,1660,1625,1440$, 1375, 1305, 1260, 1230, 1145, 990, 960, 940, 815, 750, 665. ${ }^{1} \mathrm{H} \mathrm{NMR}\left(\mathrm{CDCl}_{3}\right.$, partial assignment): $\delta 6.18(\mathrm{~d}, J$ $3.4 \mathrm{~Hz}, 1 \mathrm{H}, \mathrm{H}-13), 5.52$ (m, 1H, H-3), 5.46 (d, J $3.1 \mathrm{~Hz}$, 1H, H-13), 5.43 (m, 1H, H-9), 4.02 (dd, J 8.9 and 10.7 Hz, 1H, H-6), 3.10 - 1.50 \{13H [1.91 (bs, H-15), 1.77 (bs, $\mathrm{H}-14)]\} .{ }^{13} \mathrm{C} \mathrm{NMR}\left(\mathrm{CDCl}_{3}\right): \delta 170.09(\mathrm{C}=\mathrm{O}), 143.83(\mathrm{C})$, $139.37(\mathrm{C}), 137.19(\mathrm{C}), 125.52(\mathrm{CH}), 119.51\left(\mathrm{CH}_{2}\right), 119.33$ $(\mathrm{CH}), 86.06(\mathrm{CH}), 54.79(\mathrm{CH}), 47.79(\mathrm{CH}), 44.79(\mathrm{CH})$, $37.92\left(\mathrm{CH}_{2}\right), 29.83\left(\mathrm{CH}_{2}\right), 27.85\left(\mathrm{CH}_{3}\right), 17.63\left(\mathrm{CH}_{3}\right)$.

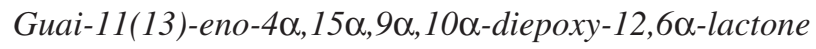
(15)

Preparation of peracetic acid solution. $\mathrm{H}_{2} \mathrm{O}_{2}(30 \%$ $25.4 \mathrm{~mL}$ ) was added to a round bottom flask containing 
glacial acetic acid $(12.6 \mathrm{~mL})$ and the mixture was stirred for 30 minutes. $\mathrm{CHCl}_{3}(21 \mathrm{~mL})$ was added and the mixture, kept in the dark, was vigorously stirred at room temperature for $24 \mathrm{~h}$. The organic layer was separated and then used in the epoxidation reaction.

Epoxidation of eremanthine (1). Eremanthine (1) $(0.300$ $\mathrm{g}, 1.302 \mathrm{mmol}$ ) was dissolved in a solution of $\mathrm{AcO}_{2} \mathrm{H} / \mathrm{CHCl}_{3}$ $(21 \mathrm{~mL})$, prepared as described above. The resulting solution was kept in the dark and stirred at room temperature for 96 h. The mixture was transferred to a separatory funnel and then washed with $\mathrm{H}_{2} \mathrm{O}(1 \times 30 \mathrm{~mL})$, aqueous $5 \% \mathrm{NaHCO}_{3}$ $(2 \times 30 \mathrm{~mL})$ and again with $\mathrm{H}_{2} \mathrm{O}(1 \times 30 \mathrm{~mL})$. The organic layer was separated and the aqueous phases were extracted with $\mathrm{CHCl}_{3}(3 \times 35 \mathrm{~mL})$. The organic extracts were dried with $\mathrm{Na}_{2} \mathrm{SO}_{4}$, filtered under activated charcoal and the solvent removed under reduced pressure to give diepoxide 15 as a colourless crystalline residue $(0.274 \mathrm{~g}, 80 \%) . \mathrm{R}_{\mathrm{f}}$ 0.40 (50\% EtOAc / hexane). IR (KBr) $v_{\max } / \mathrm{cm}^{-1}: 2915,1760$, 1670, 1465, 1440, 1410, 1380, 1265, 1150, 1090, 985, 930, 880, 815, 760, 730. ${ }^{1} \mathrm{H}$ NMR ( $\mathrm{CDCl}_{3}$, partial assignment): $\delta 6.17$ (d, $J 3.4 \mathrm{~Hz}, 1 \mathrm{H}, \mathrm{H}-13), 5.48$ (d, $J 3.2 \mathrm{~Hz}, 1 \mathrm{H}, \mathrm{H}-$ 13), 3.71 (dd, $J 9.6$ and $11.3 \mathrm{~Hz}, 1 \mathrm{H}, \mathrm{H}-6), 3.30-1.10$ $\{15 \mathrm{H}[3.14$ (d, J 4.1 Hz, H-15), 3.05 (d, J 5.0 Hz, H-9), 2.89 (d, J4.1 Hz, H-15), 1.37 (s, H-14)]\}. ${ }^{13} \mathrm{CNMR}\left(\mathrm{CDCl}_{3}\right)$ : $\delta 169.54(\mathrm{C}=\mathrm{O}), 138.58(\mathrm{C}), 119.67\left(\mathrm{CH}_{2}\right), 81.34(\mathrm{CH})$, $65.72(\mathrm{C}), 63.29(\mathrm{C}), 61.41(\mathrm{CH}), 52.14(\mathrm{CH}), 49.92\left(\mathrm{CH}_{2}\right)$, $44.88(\mathrm{CH}), 40.73(\mathrm{CH}), 28.18\left(\mathrm{CH}_{2}\right), 28.06\left(\mathrm{CH}_{2}\right), 26.33$ $\left(\mathrm{CH}_{2}\right), 26.24\left(\mathrm{CH}_{3}\right)$.

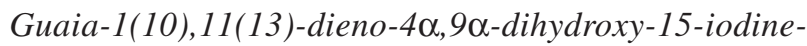
12,6 $\alpha$-lactone (18) and Guaia-1(10),11(13)-dieno-4 $\alpha$ hydroxy,9 $\alpha$-acetate-15-iodine-12,6o-lactone (19)

A mixture of diepoxide 15 (0.270 g, $1.029 \mathrm{mmol})$, KI $(0.188 \mathrm{~g}, 1.132 \mathrm{mmol})$, glacial acetic acid $(0.88 \mathrm{~mL}$, $15.435 \mathrm{mmol})$ and acetone $(1.80 \mathrm{~mL})$ was heated at reflux for $5 \mathrm{~h}$. It was then allowed to cool, diluted with EtOAc $(30 \mathrm{~mL})$ and transferred to a separatory funnel. The solution was washed with $\mathrm{H}_{2} \mathrm{O}(1 \times 30 \mathrm{~mL})$, aqueous $5 \%$ $\mathrm{NaHCO}_{3}(1 \times 30 \mathrm{~mL})$, aqueous $5 \% \mathrm{Na}_{2} \mathrm{~S}_{2} \mathrm{O}_{3}(1 \times 30 \mathrm{~mL})$ and again with $\mathrm{H}_{2} \mathrm{O}(1 \times 30 \mathrm{~mL})$. The organic layer was separated and the aqueous phases were extracted with EtOAc $(1 \times 30 \mathrm{~mL})$. The organic phases were dried with $\mathrm{Na}_{2} \mathrm{SO}_{4}$, filtered and concentrated in vacuum. It was obtained a crude product that was purified by column chromatography (50\% EtOAc / hexane). It was obtained yellowish crystals $(0.330 \mathrm{~g}, 82 \%)$ identified as iodohydrin 18. $\mathrm{R}_{\mathrm{f}} 0.16$ (50\% EtOAc / hexane); m. p. $119-120{ }^{\circ} \mathrm{C}$ (decomposition). IR (KBr) $v_{\max } / \mathrm{cm}^{-1}: 3510,3400,3030$, 2940, 2880, 1760, 1665, 1410, 1315, 1220, 1175, 1135, 1040, 950. ${ }^{1} \mathrm{H} \mathrm{NMR}\left(\mathrm{CDCl}_{3}\right.$, partial assignment): $\delta 6.22$ (d, J $3.3 \mathrm{~Hz}, 1 \mathrm{H}, \mathrm{H}-13), 5.52$ (d, J $3.1 \mathrm{~Hz}, 1 \mathrm{H}, \mathrm{H}-13$ ), 4.32 (dd, $J 2.0$ and $4.6 \mathrm{~Hz}, 1 \mathrm{H}, \mathrm{H}-9$ ), 3.85 (dd, $J 9.9$ and $11.2 \mathrm{~Hz}, 1 \mathrm{H}, \mathrm{H}-6), 3.63$ (dd, $J 2.1$ and $10.8 \mathrm{~Hz}, 1 \mathrm{H}$, $\mathrm{H}-15), 3.50-3.20$ (m, 2H, H-5 and H-7), 3.29 (d, $J 10.8$ $\mathrm{Hz}, 1 \mathrm{H}, \mathrm{H}-15), 2.55-1.10\left\{11 \mathrm{H}[1.80\right.$ (bs, H-14)] $\} .{ }^{13} \mathrm{C}$ NMR $\left(\mathrm{CDCl}_{3}\right): \delta 168.32(\mathrm{C}=\mathrm{O}), 138.13(\mathrm{C}), 134.47(\mathrm{C})$, $130.80(\mathrm{C}), 120.09\left(\mathrm{CH}_{2}\right), 83.00(\mathrm{CH}), 81.03(\mathrm{C}), 72.21$ $(\mathrm{CH}), 55.93(\mathrm{CH}), 41.66(\mathrm{CH}), 37.22\left(\mathrm{CH}_{2}\right), 33.03\left(\mathrm{CH}_{2}\right)$, $30.02\left(\mathrm{CH}_{2}\right), 22.78\left(\mathrm{CH}_{3}\right), 14.87\left(\mathrm{CH}_{2}\right)$.

Iodohydrin 18 (0.155 g, $0.397 \mathrm{mmol})$ was dissolved in acetic anhydride $(2.70 \mathrm{~mL})$ and to resulting solution was added pyridine $(0.67 \mathrm{~mL})$. The mixture was stirred at room temperature for $2 \mathrm{~h}$ and then diluted with EtOAc $(20 \mathrm{~mL})$, transferred to a beaker containing pricked ice and then stirred for $10 \mathrm{~min}$. The aqueous phase was separated and organic layer was washed with aqueous $5 \%$ $\mathrm{NaHCO}_{3}(1 \times 20 \mathrm{~mL})$ and $\mathrm{H}_{2} \mathrm{O}(1 \times 20 \mathrm{~mL})$. The organic layer was separated and the aqueous phases were extracted with EtOAc $(1 \times 20 \mathrm{~mL})$. The organic layers were dried with $\mathrm{Na}_{2} \mathrm{SO}_{4}$, filtered and concentrated in vacuum to give: Allylic acetate $19(0.155 \mathrm{~g}, 90 \%)$ as a brownish oil. $\mathrm{R}_{\mathrm{f}}$ 0.50 (50\% EtOAc / hexane). IR (film) $v_{\max } / \mathrm{cm}^{-1}: 3500$, 2940, 1770, 1730, 1440, 1375, 1240, 1140, 1040, 980, 960, 920, 820, 760, 735. ${ }^{1} \mathrm{H}$ NMR $\left(\mathrm{CDCl}_{3}\right.$, partial assignment): $\delta 6.23$ (d, J $3.3 \mathrm{~Hz}, 1 \mathrm{H}, \mathrm{H}-13), 5.49$ (d, J 3.0 $\mathrm{Hz}, 1 \mathrm{H}, \mathrm{H}-13), 5.40$ (m, 1H, H-9), 3.87 (dd, J 9.9 and $11.2 \mathrm{~Hz}, 1 \mathrm{H}, \mathrm{H}-6), 3.66(\mathrm{dd}, J 2.2$ and $10.8 \mathrm{~Hz}, 1 \mathrm{H}$, $\mathrm{H}-15), 3.40-3.20$ (m, 1H, H-7), 3.31 (d, J $10.8 \mathrm{~Hz}, 1 \mathrm{H}$, $\mathrm{H}-15), 3.14$ (m, 1H, H-5), $2.40-1.15\{13 \mathrm{H}[2.05$ (s, $\left.-\mathrm{OCOCH}_{3}\right), 1.74$ (bs, $\left.\left.\left.\mathrm{H}-14\right)\right]\right\} .{ }^{13} \mathrm{C} \mathrm{NMR}\left(\mathrm{CDCl}_{3}\right): \delta 170.36$ $(\mathrm{C}=\mathrm{O}), 168.81(\mathrm{C}=\mathrm{O}), 137.67(\mathrm{C}), 137.25(\mathrm{C}), 130.15$ (C), $120.15\left(\mathrm{CH}_{2}\right), 82.61(\mathrm{CH}), 81.00(\mathrm{C}), 73.36(\mathrm{CH})$, $55.83(\mathrm{CH}), 42.58(\mathrm{CH}), 37.19\left(\mathrm{CH}_{2}\right), 30.37\left(\mathrm{CH}_{2}\right), 30.09$ $\left(\mathrm{CH}_{2}\right), 22.51\left(\mathrm{CH}_{3}\right), 21.18\left(\mathrm{CH}_{3}\right), 14.84\left(\mathrm{CH}_{2}\right)$.

Guaia-1(10),4(15),11(13)-trieno-9 $\alpha$-acetate-12,6 $\alpha$ lactone (11); Guaia-1(10),4(15), 11(13)-trieno-9 $\alpha$ -

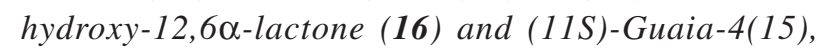

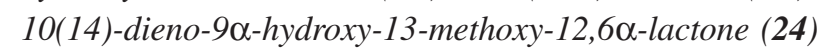

\section{General procedure for preparation of allylic derivatives 11, 16 and 24}

To a botton round flask containing the appropriate iodohydrin 18 / 19 / 20 (0.355 mmol) it was added powdered zinc $(0.348 \mathrm{~g}, 5.325 \mathrm{mmol})$, ethanol $(5.50 \mathrm{~mL})$ and glacial acetic acid $(0.10 \mathrm{~mL}, 1.775 \mathrm{mmol})$. The mixture, under magnetic stirring, was heated at reflux for $30 \mathrm{~min}$. After allowed to cool at room temperature, the mixture was filtered, washing the zinc with ethanol (20 $\mathrm{mL}) . \mathrm{H}_{2} \mathrm{O}(50 \mathrm{~mL})$ was added and then concentrated in vacuum. The concentrated mixture was extracted with 
EtOAc $(1 \times 50 \mathrm{~mL})$. The aqueous phase was separated and organic layer was washed with aqueous $5 \% \mathrm{NaHCO}_{3}$ $(1 \times 50 \mathrm{~mL})$ and $\mathrm{H}_{2} \mathrm{O}(1 \times 50 \mathrm{~mL})$. The organic layer was separated and aqueous phases were extracted with EtOAc (1 x $50 \mathrm{~mL}$ ). The organic layers were dried with $\mathrm{Na}_{2} \mathrm{SO}_{4}$, filtered and concentrated in vacuum.

Allylic alcohol $16(0.085 \mathrm{~g}, 98 \%)$ as a yellowish oil. $\mathrm{R}_{\mathrm{f}} 0.40$ (50\% EtOAc / hexane). IR (film) $\mathrm{v}_{\max } / \mathrm{cm}^{-1}: 3450$, 2920, 1760, 1660, 1440, 1410, 1375, 1310, 1260, 1145, 980, 760. ${ }^{1} \mathrm{H} \mathrm{NMR}\left(\mathrm{CDCl}_{3}\right.$, partial assignment): $\delta 6.10$ (d, J $3.3 \mathrm{~Hz}, 1 \mathrm{H}, \mathrm{H}-13), 5.36$ (d, J $3.1 \mathrm{~Hz}, 1 \mathrm{H}, \mathrm{H}-13$ ), 5.17 (bs, 1H, H-15), 5.07 (bs, 1H, H-15), 4.33 (dd, J 1.3 and $3.9 \mathrm{~Hz}, 1 \mathrm{H}, \mathrm{H}-9), 3.80-3.40\{3 \mathrm{H}[3.68(\mathrm{t}, J 10.1 \mathrm{~Hz}$, $\mathrm{H}-6)]\}, 2.60-1.10\left\{10 \mathrm{H}\left[1.82\right.\right.$ (bs, H-14)]\}. ${ }^{13} \mathrm{C}$ NMR $\left(\mathrm{CDCl}_{3}\right): \delta 170.03(\mathrm{C}=\mathrm{O}), 149.26(\mathrm{C}), 140.19(\mathrm{C}), 138.31$ (C), $132.72(\mathrm{C}), 117.51\left(\mathrm{CH}_{2}\right), 110.29\left(\mathrm{CH}_{2}\right), 82.13(\mathrm{CH})$, $71.94(\mathrm{CH}), 50.80(\mathrm{CH}), 43.50(\mathrm{CH}), 32.30\left(\mathrm{CH}_{2}\right), 32.07$ $\left(\mathrm{CH}_{2}\right), 29.48\left(\mathrm{CH}_{2}\right), 22.36\left(\mathrm{CH}_{3}\right) . \mathrm{m} / \mathrm{z}(\%): 246\left(\mathrm{M}^{+}, 14 \%\right)$, 228 (8), 213 (4), 185 (6), 157 (6), 149 (17), 133 (22), 123 (8), 107 (11), 91 (19), 83 (100), 71 (14).

Allylic acetate $11(0.100 \mathrm{~g}, 98 \%)$ as a colourless oil. $\mathrm{R}_{\mathrm{f}} 0.65$ (50\% EtOAc / hexane). IR (film) $\mathrm{v}_{\max } / \mathrm{cm}^{-1}: 2940$, $1770,1740,1660,1445,1370,1240,1135,1020,740 .{ }^{1} \mathrm{H}$ NMR $\left(\mathrm{CDCl}_{3}\right.$, partial assignment): $\delta 6.10(\mathrm{~d}, J 3.4 \mathrm{~Hz}$, 1H, H-13), 5.34 (d, J 3.1 Hz, 1H, H-13), 5.24 (dd, J 1.3 and $5.5 \mathrm{~Hz}, 1 \mathrm{H}, \mathrm{H}-9), 5.16$ (d, J $1.1 \mathrm{~Hz}, 1 \mathrm{H}, \mathrm{H}-15), 5.08$ (d, $J 1.1 \mathrm{~Hz}, 1 \mathrm{H}, \mathrm{H}-15), 3.68$ (dd, J 9.6 and $10.5 \mathrm{~Hz}, 1 \mathrm{H}$, H-6), 3.54 (bd, J 10.2 Hz, 1H, H-5), 3.30 (m, 1H, H-7), $2.70-1.10\left\{12 \mathrm{H}\left[2.05\left(\mathrm{~s},-\mathrm{OCOCH}_{3}\right), 1.82(\mathrm{~d}, J 1.2 \mathrm{~Hz}\right.\right.$, $\mathrm{H}-14)]\} .{ }^{13} \mathrm{C} \mathrm{NMR}\left(\mathrm{CDCl}_{3}\right): \delta 170.27(\mathrm{C}=\mathrm{O}), 169.38$ (C=O), 148.83 (C), 140.98 (C), 139.77 (C), 129.91 (C), $117.72\left(\mathrm{CH}_{2}\right), 110.84\left(\mathrm{CH}_{2}\right), 81.42(\mathrm{CH}), 73.82(\mathrm{CH})$, $51.04(\mathrm{CH}), 44.85(\mathrm{CH}), 32.31\left(\mathrm{CH}_{2}\right), 32.03\left(\mathrm{CH}_{2}\right), 29.74$ $\left(\mathrm{CH}_{2}\right), 22.09\left(\mathrm{CH}_{3}\right), 21.06\left(\mathrm{CH}_{3}\right)$.

The crude product obtained from iodohydrin $\mathbf{2 0}$ was filtered by column of silica gel ( $50 \%$ EtOAc / hexane) to give: Allylic alcohol $24(0.090 \mathrm{~g}, 91 \%)$ as a colourless oil. $\mathrm{R}_{\mathrm{f}} 0.25$ (50\% EtOAc / hexane). IR (film) $\mathrm{v}_{\max } / \mathrm{cm}^{-1}$ : 3450, 2930, 1775, 1660, 1440, 1380, 1320, 1180, 1100, 910, 760. ${ }^{1} \mathrm{H} \mathrm{NMR}\left(\mathrm{CDCl}_{3}\right.$, partial assignment): $\delta 5.14$ (d, J $2.3 \mathrm{~Hz}, 1 \mathrm{H}, \mathrm{H}-15), 5.00$ (bs, 2H, H-14 and H-15), 4.80 (bs, 1H, H-14), 4.48 (t, J 3.5 Hz, 1H, H-9), 3.86 (t, J 9.4 Hz, 1H, H-6), 3.63 (m, 2H, H-13), 3.45 (m, 1H, H-5), $3.34\left(\mathrm{~s},-\mathrm{OCH}_{3}\right), 2.90-1.10\{10 \mathrm{H}[2.77(\mathrm{~m}, \mathrm{H}-7)]\} .{ }^{13} \mathrm{C}$ NMR $\left(\mathrm{CDCl}_{3}\right): \delta 176.05(\mathrm{C}=\mathrm{O}), 151.81(\mathrm{C}), 151.56(\mathrm{C})$, $112.23\left(\mathrm{CH}_{2}\right), 108.74\left(\mathrm{CH}_{2}\right), 85.77(\mathrm{CH}), 74.39(\mathrm{CH})$, $69.27\left(\mathrm{CH}_{2}\right), 59.29\left(\mathrm{CH}_{3}\right), 51.47(\mathrm{CH}), 47.53(\mathrm{CH}), 40.07$ $\left(\mathrm{CH}_{2}\right), 38.95(\mathrm{CH}), 38.49(\mathrm{CH}), 32.73\left(\mathrm{CH}_{2}\right), 29.67\left(\mathrm{CH}_{2}\right)$. Literature: ${ }^{17} \mathrm{R}_{\mathrm{f}} 0.27$ (50\% EtOAc / hexane). IR (KBr) $v_{\max } / \mathrm{cm}^{-1}: 3353,1771,1186 .{ }^{1} \mathrm{H}$ NMR (100 MHz, CDCl ${ }_{3}$, partial assignment): $\delta 5.15(\mathrm{~d}, J 2.5 \mathrm{~Hz}, 1 \mathrm{H}, \mathrm{H}-15), 5.03$ (bs, 1H, H-15), 5.01 (bs, 1H, H-14), 4.82 (bs, 1H, H-14), 4.49 (t, J $3.5 \mathrm{~Hz}, 1 \mathrm{H}, \mathrm{H}-9), 3.88$ (t, J $9.5 \mathrm{~Hz}, 1 \mathrm{H}, \mathrm{H}-6)$, 3.66 (d, J $4.0 \mathrm{~Hz}, 2 \mathrm{H}, \mathrm{H}-13), 3.37$ (s, 3H, $-\mathrm{OCH}_{3}$ ).

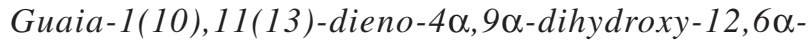
lactone (17)

A solution of diol 21 (0.100 g, $0.337 \mathrm{mmol}), \mathrm{DMF}$ (2.4 $\mathrm{mL})$ and aqueous $4 \mathrm{~mol} \mathrm{~L}-1 \mathrm{NaOH}(0.46 \mathrm{~mL}, 1.853 \mathrm{mmol})$ was heated at reflux for $2 \mathrm{~h}$. The mixture was allowed to cool at room temperature and it was added dropwise an aqueous solution of $10 \%$ (v/v) $\mathrm{HCl}$ until $\mathrm{pH} 3$. EtOAc (25 $\mathrm{mL})$ was added and solution was washed with $\mathrm{H}_{2} \mathrm{O}(2 \times 30$ $\mathrm{mL})$. The organic layer was separated and the aqueous phases were extracted with EtOAc $(3 \times 30 \mathrm{~mL})$. The organic phases were dried with $\mathrm{Na}_{2} \mathrm{SO}_{4}$, filtered and concentrated in vacuum. The crude product was purified by column chromatography of silica gel eluted with $80 \%$ EtOAc / hexane. It was obtained a colourless oil (0.067 g, 75\%) identified by ${ }^{1} \mathrm{H}$ NMR as the $\alpha$-methylene- $\gamma$-lactone $\mathbf{1 7}$ in mixture with other lactone later identified as the substance 27. The proportion of these lactones was $3: 1$ in favor of the substance 17 ( ${ }^{1} \mathrm{H}$ NMR). Substance 17: $\mathrm{R}_{\mathrm{f}} 0.13(50 \%$ EtOAc / hexane). IR (KBr) $v_{\max } / \mathrm{cm}^{-1}: 3450,2920,1760$, 1660, 1450, 1380, 1140, 990. ${ }^{1} \mathrm{H} \mathrm{NMR}\left(\mathrm{CDCl}_{3}\right.$, partial assignment): $\delta 6.20$ (d, J $3.4 \mathrm{~Hz}, 1 \mathrm{H}, \mathrm{H}-13), 5.50$ (d, $J 3.1$ Hz, 1H, H-13), 4.32 (m, 1H, H-9), 3.85 (dd, J 9.9 and 10.7 Hz, 1H, H-6), 3.35 (m, 1H, H-7), 2.89 (m, 1H, H-5), 2.60 $1.10\{14 \mathrm{H}[1.81$ (d, J 1.2 Hz, H-14), 1.27 (s, H-15)]\}.

Guaia-1(10),4(15), 11(13)-trieno-9 $\alpha$-acetate-12, $6 \alpha$ lactone (11) and Guaia-1(10),11(13)-dieno-4 $\alpha$ hydroxy, $9 \alpha$-acetate-12,6 $\alpha$-lactone (13)

General procedure for preparation of allylic acetates 11 and 13

The appropriate allylic alcohol 16 / (17+27) (0.227 mmol) was dissolved in acetic anhydride $(1.54 \mathrm{~mL})$ and to resulting solution was added pyridine $(0.38 \mathrm{~mL})$. The mixture was stirred at room temperature for $2 \mathrm{~h}$ and then diluted with EtOAc $(30 \mathrm{~mL})$, transferred to a beaker containing pricked ice and then stirred for $10 \mathrm{~min}$. The aqueous phase was separated and organic layer was washed with aqueous $5 \% \mathrm{NaHCO}_{3}(1 \times 20 \mathrm{~mL})$ and $\mathrm{H}_{2} \mathrm{O}$ $(1 \times 20 \mathrm{~mL})$. The organic layer was separated and aqueous phases were extracted with EtOAc $(1 \times 30 \mathrm{~mL})$. The organic layers were dried with $\mathrm{Na}_{2} \mathrm{SO}_{4}$, filtered and concentrated in vacuum.

Allylic acetate $11(0.062 \mathrm{~g}, 95 \%)$ as a colourless oil. $\mathrm{R}_{\mathrm{f}} 0.65$ (50\% EtOAc / hexane). 
The crude product obtained from the acetylation of epimeric mixture $(\mathbf{1 7 + 2 7})$ was purified by column chromatography of silica gel eluted with $\mathrm{CHCl}_{3}$ and EtOAc to give: Allylic acetate $13(0.038 \mathrm{~g}, 54 \%)$ as a colourless oil. Crystallization in $\mathrm{CHCl}_{3}$ yielded $\mathbf{1 3}$ as colourless crystals [m.p. 132 - $134^{\circ} \mathrm{C}$ ]. $\mathrm{R}_{\mathrm{f}} 0.37$ (50\% EtOAc / hexane). IR (film) $v_{\max } / \mathrm{cm}^{-1}: 3500,2940,1775,1735,1670,1440$, 1375, 1240, 1140, 990, 960, 820, 735. ${ }^{1} \mathrm{H} \mathrm{NMR}\left(\mathrm{CDCl}_{3}\right.$, partial assignment): $\delta 6.18$ (d, $J 3.3 \mathrm{~Hz}, 1 \mathrm{H}, \mathrm{H}-13), 5.45$ (d, J 3.1 Hz, 1H, H-13), 5.39 (dd, J 2.0 and $4.7 \mathrm{~Hz}, 1 \mathrm{H}, \mathrm{H}-$ 9), 3.85 (dd, $J 10.2$ and $10.8 \mathrm{~Hz}, 1 \mathrm{H}, \mathrm{H}-6), 3.14$ (m, 1H, H7), 2.90 (m, 1H, H-5), 2.60 - $1.10\left\{16 \mathrm{H}\left[2.03\right.\right.$ (s, - $\mathrm{OCOCH}_{3}$ ), 1.72 (bs, H-14), 1.27 (s, H-15)]\}. ${ }^{13} \mathrm{C} \mathrm{NMR}\left(\mathrm{CDCl}_{3}\right)$ : $\delta 170.49(\mathrm{C}=\mathrm{O}), 169.24(\mathrm{C}=\mathrm{O}), 138.67(\mathrm{C}), 138.22(\mathrm{C})$, $129.12(\mathrm{C}), 119.64\left(\mathrm{CH}_{2}\right), 83.50(\mathrm{CH}), 80.18(\mathrm{C}), 73.65$ $(\mathrm{CH}), 57.84(\mathrm{CH}), 42.27(\mathrm{CH}), 37.85\left(\mathrm{CH}_{2}\right), 30.61\left(\mathrm{CH}_{2}\right)$, $30.48\left(\mathrm{CH}_{2}\right), 22.59\left(\mathrm{CH}_{3}\right), 22.45\left(\mathrm{CH}_{3}\right), 21.21\left(\mathrm{CH}_{3}\right)$.

General procedure for the reactions of lactonic fusion inversion of substances $\mathbf{8 - 1 3}$

A common procedure is described for the reaction of lactonic fusion inversion of substance $\mathbf{8}$. To a botton round flask containing the substance $8(0.013 \mathrm{~g}, 0.056 \mathrm{mmol})$ an aqueous solution of $4 \% \mathrm{KOH}(0.36 \mathrm{~mL}, 0.258 \mathrm{mmol})$ was added and it was left under magnetic stirring at the temperature and time indicated in Table 3 (Exp. 1). After total solubilization of the substrate, TLC revealed consumption of starting material. The mixture was concentrated under reduced pressure and then dried in high vacuum. The carboxylic salt was dissolved in THF $(0.56$ $\mathrm{mL}$ ) and then put in a bath of ice at the temperature of $0{ }^{\circ} \mathrm{C}$ under magnetic stirring. $\mathrm{Et}_{3} \mathrm{~N}(0.055 \mathrm{~mL}, 0.392 \mathrm{mmol})$ and $\mathrm{MsCl}(0.026 \mathrm{~mL}, 0.336 \mathrm{mmol})$ were added to solution and after $1 \mathrm{~h}$ the bath of ice was removed and mixture was left at room temperature for $3 \mathrm{~h}$. Soon afterwards, an aqueous solution of $0.2 \mathrm{~mol} \mathrm{~L}^{-1} \mathrm{NaOH}(0.90 \mathrm{~mL}, 0.179 \mathrm{mmol})$ was added and the mixture was put in a bath at the temperature of $50{ }^{\circ} \mathrm{C}$ for $1 \mathrm{~h}$. The mixture was allowed to cool at room temperature and an aqueous $10 \%$ (v/v) $\mathrm{HCl}$ was added dropwise until pH 3. It was diluted with EtOAc $(20 \mathrm{~mL})$ and then washed with $\mathrm{H}_{2} \mathrm{O}(2 \times 20 \mathrm{~mL})$. The organic layer was separated and the aqueous phases were extracted with EtOAc $(1 \times 20 \mathrm{~mL})$. The organic phases were dried with $\mathrm{Na}_{2} \mathrm{SO}_{4}$, filtered and concentrated in vacuum. It was obtained: crude product $(0.012 \mathrm{~g}, 92 \%) .{ }^{1} \mathrm{H} \mathrm{NMR}\left(\mathrm{CDCl}_{3}\right)$ : partial assignment for the substance 32 (see Table 4).

Lactonic fusion inversion of substance 9 (Exp. 2 - Table 3)

The reaction was executed following general procedure, using $9(0.016 \mathrm{~g}, 0.068 \mathrm{mmol})$ and aqueous solution of $4 \% \mathrm{KOH}(0.44 \mathrm{~mL}, 0.313 \mathrm{mmol})$. The dry carboxylic salt was dissolved in THF $(0.68 \mathrm{~mL})$ and it was added to resulting solution $\mathrm{Et}_{3} \mathrm{~N}(0.066 \mathrm{~mL}, 0.476$ $\mathrm{mmol})$ and $\mathrm{MsCl}(0.032 \mathrm{~mL}, 0.408 \mathrm{mmol})$. After the time of reaction, aqueous solution of $0.2 \mathrm{~mol} \mathrm{~L}^{-1} \mathrm{NaOH}(1.09$ $\mathrm{mL}, 0.218 \mathrm{mmol}$ ) was added and the mixture was warmed in a bath at $50{ }^{\circ} \mathrm{C}$ for $1 \mathrm{~h}$. The mixture was neutralized with $10 \%(\mathrm{v} / \mathrm{v}) \mathrm{HCl}$ until $\mathrm{pH} 3$ and then extracted with EtOAc. It was obtained: crude product $(0.015 \mathrm{~g}, 94 \%)$. ${ }^{1} \mathrm{H}$ NMR $\left(\mathrm{CDCl}_{3}\right)$ : partial assignment for the substance 34 (see Table 4).

\section{Lactonic fusion inversion of substance 10 (Exp. 3 - Table 3)}

The reaction was executed following general procedure, using 10 (0.012 g, $0.052 \mathrm{mmol})$ and aqueous solution of $4 \% \mathrm{KOH}(0.34 \mathrm{~mL}, 0.239 \mathrm{mmol})$. The dry carboxylic salt was dissolved in THF $(2.40 \mathrm{~mL})$ and it was added to resulting solution $\mathrm{Et}_{3} \mathrm{~N}(0.051 \mathrm{~mL}, 0.364 \mathrm{mmol})$ and $\mathrm{MsCl}$ $(0.024 \mathrm{~mL}, 0.312 \mathrm{mmol})$. After the time of reaction, aqueous solution of $0.2 \mathrm{~mol} \mathrm{~L}^{-1} \mathrm{NaOH}(0.83 \mathrm{~mL}, 0.166 \mathrm{mmol})$ was added and the mixture was warmed in a bath at $50{ }^{\circ} \mathrm{C}$ for 1 h. The mixture was neutralized with $10 \%$ (v/v) $\mathrm{HCl}$ until pH 3 and then extracted with EtOAc. It was obtained: crude product $(0.011 \mathrm{~g}, 92 \%)$. Due to difference of polarity between the two substances of this mixture, we proceeded to purification by column chromatography of silica gel (20\% EtOAc / hexane) and it was separated a fraction as a colourless oil, identified as 6-epi-isoeremanthine (36). $\mathrm{R}_{\mathrm{f}}$ 0.69 (50\% EtOAc / hexane). IR (film) $\mathrm{v}_{\max } / \mathrm{cm}^{-1}: 3050$, 2920, 2850, 1765, 1660, 1610, 1460, 1380, 1270, 1155, 820. ${ }^{1} \mathrm{H}$ NMR $\left(\mathrm{CDCl}_{3}\right.$, partial assignment): $\delta 6.24$ (d, $J 2.1$ $\mathrm{Hz}, 1 \mathrm{H}, \mathrm{H}-13), 5.58$ (d, J $1.9 \mathrm{~Hz}, 1 \mathrm{H}, \mathrm{H}-13), 5.52$ (m, 1H, H-3), 5.21 (m, 1H, H-9), 4.78 (bd, J 8.0 Hz, 1H, H-6), 3.40 - $1.50\{13 \mathrm{H}[1.74$ (d, J 1.6 Hz, H-15), 1.63 (d, J 1.3 Hz, H14)]\}.

Lactonic fusion inversion of substance 11 (Exp. 4 - Table 3)

The reaction was executed following general procedure, using $11(0.011 \mathrm{~g}, 0.038 \mathrm{mmol})$ and aqueous solution of $4 \% \mathrm{KOH}(0.25 \mathrm{~mL}, 0.175 \mathrm{mmol})$. The dry carboxylic salt was dissolved in THF $(0.87 \mathrm{~mL})$ and it was added to resulting solution $\mathrm{Et}_{3} \mathrm{~N}(0.037 \mathrm{~mL}, 0.266$ $\mathrm{mmol})$ and $\mathrm{MsCl}(0.017 \mathrm{~mL}, 0.228 \mathrm{mmol})$. After the time of reaction, aqueous solution of $0.2 \mathrm{~mol} \mathrm{~L}^{-1} \mathrm{NaOH}(0.61$ $\mathrm{mL}, 0.122 \mathrm{mmol}$ ) was added and the mixture was warmed in a bath at $50{ }^{\circ} \mathrm{C}$ for $1 \mathrm{~h}$. The mixture was neutralized with $10 \%(\mathrm{v} / \mathrm{v}) \mathrm{HCl}$ until $\mathrm{pH} \mathrm{3}$, filtered to remove a supposed insoluble polymeric material and then extracted 
with EtOAc. It was obtained: crude product (0.005 g, $46 \%)$. ${ }^{1} \mathrm{H} \mathrm{NMR}\left(\mathrm{CDCl}_{3}\right)$ : partial assignment for the substance $\mathbf{3 8}$ (see Table 4).

Lactonic fusion inversion of substance 12 (Exp. 5 - Table 3)

The reaction was executed following general procedure, using 12 (0.009 g, $0.036 \mathrm{mmol})$ and aqueous solution of $4 \% \mathrm{KOH}(0.23 \mathrm{~mL}, 0.166 \mathrm{mmol})$. The dry carboxylic salt was dissolved in THF $(0.35 \mathrm{~mL})$ and it was added to resulting solution $\mathrm{Et}_{3} \mathrm{~N}(0.035 \mathrm{~mL}, 0.252$ $\mathrm{mmol})$ and $\mathrm{MsCl}(0.017 \mathrm{~mL}, 0.216 \mathrm{mmol})$. After the time of reaction, aqueous solution of $0.2 \mathrm{~mol} \mathrm{~L}^{-1} \mathrm{NaOH}(0.58$ $\mathrm{mL}, 0.115 \mathrm{mmol}$ ) was added and the mixture was warmed in a bath at $50{ }^{\circ} \mathrm{C}$ for $1 \mathrm{~h}$. The mixture was neutralized with $10 \%(\mathrm{v} / \mathrm{v}) \mathrm{HCl}$ until $\mathrm{pH} 3$ and then extracted with EtOAc. It was obtained: crude product (0.008 g, 89\%). ${ }^{1} \mathrm{H}$ NMR $\left(\mathrm{CDCl}_{3}\right)$ : partial assignment for the substance 40 (see Table 4).

Lactonic fusion inversion of substance 13 (Exp. 6 - Table 3)

The reaction was executed following general procedure, using 13 (0.030 g, $0.098 \mathrm{mmol})$ and aqueous solution of $4 \% \mathrm{KOH}(0.63 \mathrm{~mL}, 0.451 \mathrm{mmol})$. The dry carboxylic salt was dissolved in DMSO $(1.10 \mathrm{~mL})$ and it was added to resulting solution $\mathrm{Et}_{3} \mathrm{~N}(0.096 \mathrm{~mL}, 0.686$ $\mathrm{mmol})$ and $\mathrm{MsCl}(0.045 \mathrm{~mL}, 0.588 \mathrm{mmol})$. After the time of reaction, aqueous solution of $0.2 \mathrm{~mol} \mathrm{~L}^{-1} \mathrm{NaOH}$ (1.57 $\mathrm{mL}, 0.314 \mathrm{mmol}$ ) was added and the mixture was warmed in a bath at $50{ }^{\circ} \mathrm{C}$ for $1 \mathrm{~h}$. The mixture was neutralized with $10 \%$ (v/v) $\mathrm{HCl}$ until $\mathrm{pH} 3$ and then extracted with EtOAc. It was obtained: crude product $(0.019 \mathrm{~g}, 73 \%)$. ${ }^{1} \mathrm{H} \mathrm{NMR}\left(\mathrm{CDCl}_{3}\right)$ : partial assignment for the substance 27 (see Table 4).

Lactonic fusion inversion of substance 13 (Exp. 7 - Table 3)

The reaction was executed following general procedure, using $13(0.007 \mathrm{~g}, 0.023 \mathrm{mmol})$ and aqueous solution of $4 \% \mathrm{KOH}(0.15 \mathrm{~mL}, 0.106 \mathrm{mmol})$. The dry carboxylic salt was dissolved in THF $(0.50 \mathrm{~mL})$ and it was added to resulting solution $\mathrm{Et}_{3} \mathrm{~N}(0.022 \mathrm{~mL}, 0.161$ $\mathrm{mmol})$ and $\mathrm{MsCl}(0.011 \mathrm{~mL}, 0.138 \mathrm{mmol})$. After the time of reaction, aqueous solution of $0.2 \mathrm{~mol} \mathrm{~L}^{-1} \mathrm{NaOH}(0.37$ $\mathrm{mL}, 0.074 \mathrm{mmol}$ ) was added and the mixture was warmed in a bath at $50{ }^{\circ} \mathrm{C}$ for $1 \mathrm{~h}$. The mixture was neutralized with $10 \%(\mathrm{v} / \mathrm{v}) \mathrm{HCl}$ until $\mathrm{pH} 3$ and then extracted with EtOAc. It was obtained: crude product $(0.006 \mathrm{~g}, 91 \%)$. ${ }^{1} \mathrm{H} \mathrm{NMR}\left(\mathrm{CDCl}_{3}\right)$ : partial assignment for the substance 28 (see Table 4).
Regeneration of $\alpha$-methylene- $\gamma$-lactone by methanol elimination using $\mathrm{CH}_{3} \mathrm{CN}$ as the solvent

Eremanthine (1). A solution of eremanthine methoxy derivative (14) $(0.021 \mathrm{~g}, 0.080 \mathrm{mmol})$ in $\mathrm{CH}_{3} \mathrm{CN}(0.52$ $\mathrm{mL})$ and aqueous $4 \mathrm{~mol} \mathrm{~L}{ }^{-1} \mathrm{NaOH}(0.11 \mathrm{~mL}, 0.44 \mathrm{mmol})$ was heated at reflux for $5 \mathrm{~h}$. After allowed to cool at room temperature, aqueous $10 \%(\mathrm{v} / \mathrm{v}) \mathrm{HCl}$ was added dropwise until $\mathrm{pH}$ 3. EtOAc $(20 \mathrm{~mL})$ was added and solution was washed with $\mathrm{H}_{2} \mathrm{O}(2 \times 20 \mathrm{~mL})$. The organic layer was separated and aqueous phases were extracted with EtOAc $(2 \times 20 \mathrm{~mL})$. The organic phases were dried with $\mathrm{Na}_{2} \mathrm{SO}_{4}$, filtered and concentrated in vacuum. It was obtained a brownish oil $(0.017 \mathrm{~g}, 94 \%)$ characterized as eremanthine (1). Eremanthine (1): $\mathrm{R}_{\mathrm{f}} 0.75$ (50\% EtOAc / hexane). IR $(\mathrm{KBr}) v_{\max } / \mathrm{cm}^{-1}: 2910,1760,1655,1440,1405,1380$, 1315, 1255, 1130, 1060, 1005, 890, 820. ${ }^{1} \mathrm{H} \mathrm{NMR}\left(\mathrm{CDCl}_{3}\right.$, partial assignment): $\delta 6.17(\mathrm{~d}, J 2.6 \mathrm{~Hz}, 1 \mathrm{H}, \mathrm{H}-13), 5.50$ (bd, J $7.3 \mathrm{~Hz}, 1 \mathrm{H}, \mathrm{H}-9), 5.44$ (d, J $2.3 \mathrm{~Hz}, 1 \mathrm{H}, \mathrm{H}-13$ ), 5.18 (bs, 1H, H-15), 5.01 (bs, 1H, H-15), 3.91 (t, J 9.3 $\mathrm{Hz}, 1 \mathrm{H}, \mathrm{H}-6), 2.90-1.40\left\{12 \mathrm{H}[1.80\right.$ (bs, H-14)] $\} .{ }^{13} \mathrm{C}$ NMR $\left(\mathrm{CDCl}_{3}\right): \delta 169.91(\mathrm{C}=\mathrm{O}), 149.86(\mathrm{C}), 139.86(\mathrm{C})$, $137.89(\mathrm{C}), 120.60(\mathrm{CH}), 119.30\left(\mathrm{CH}_{2}\right), 110.72\left(\mathrm{CH}_{2}\right)$, $83.10(\mathrm{CH}), 52.35(\mathrm{CH}), 46.86(\mathrm{CH}), 45.11(\mathrm{CH}), 30.37$ $\left(\mathrm{CH}_{2}\right), 29.40\left(\mathrm{CH}_{2}\right), 28.94\left(\mathrm{CH}_{2}\right), 27.82\left(\mathrm{CH}_{3}\right)$.

Mixture of epimers 17 and 27. A solution of diol 21 $(0.012 \mathrm{~g}, 0.040 \mathrm{mmol})$ in $\mathrm{CH}_{3} \mathrm{CN}(0.27 \mathrm{ml})$ and aqueous $4 \mathrm{~mol} \mathrm{~L}{ }^{-1} \mathrm{NaOH}(0.055 \mathrm{~mL}, 0.220 \mathrm{mmol})$ was heated at reflux for $3 \mathrm{~h}$. After allowed to cool at room temperature, $10 \%(\mathrm{v} / \mathrm{v}) \mathrm{HCl}$ was added dropwise until $\mathrm{pH} 3$. EtOAc ( $20 \mathrm{~mL}$ ) was added and solution was washed with $\mathrm{H}_{2} \mathrm{O}$ (2 $\times 20 \mathrm{~mL}$ ). The organic layer was separated and the aqueous phases were exhaustively extracted with EtOAc (3 x 20 $\mathrm{mL}$ ). The organic phases were dried with $\mathrm{Na}_{2} \mathrm{SO}_{4}$, filtered and concentrated in vacuum. It was obtained a brownish oil $(0.008 \mathrm{~g}, 73 \%)$ identified as a mixture of epimers $\mathbf{1 7}$ and 27 in a respective proportion of 5:6 $\left({ }^{1} \mathrm{H}\right.$ NMR). $\mathrm{R}_{\mathrm{f}}$ 0.13 (50\% EtOAc / hexane). ${ }^{1} \mathrm{H} \mathrm{NMR}\left(\mathrm{CDCl}_{3}\right)$ : partial assignment to epimers 17 and 27 (see Table 4).

\section{Supplementary Information}

This supplementary material displays some sterochemical aspects of the lactonic inversion reaction of models 8-13. This material is available free of charge via the Internet at http://jbcs.sbq.org.br.

\section{Acknowledgments}

J. C. F. A. thanks CNPq for the fellowship, DequimUFRRJ for running the NMR and IR spectra, NPPN- 
UFRJ for the mass spectrum of allylic alcohol $\mathbf{1 6}$ and the referees as well as the JBCS editorial staff for helpful suggestions.

\section{References}

1. Fraga, B. M.; Nat. Prod. Rep. 2005, 22, 465; Ibid. 2006, 23, 943.

2. Vichnewski, W.; Gilbert, B.; Phytochem. 1972, 11, 2563; Baker, P. M.; Fortes, C. C.; Fortes, E. C.; Gazzinelli, G.; Gilbert, B.; Lopes, J. N. C.; Pellegrino, J.; Tomassini, T. C. B.; Vichnewski, W.; J. Pharm. Pharmacol. 1972, 24, 853; Corbella, A.; Gariboldi, P.; Jommi, G.; Ferrari, G.; Phytochem. 1974, 13, 459; Lima, P. D. D. B.; M.Sc. Dissertation, NPPN, Universidade Federal do Rio de Janeiro, Brazil, 1983.

3. Vajs, V.; Nevescanin, M.; Macura, S.; Juranic, N.; Menkovic, N.; Milosavljevic, S.; Fitoterapia 2003, 74, 508.

4. Goldsby, G.; Burke, B. A.; Phytochem. 1987, 26, 1059.

5. Money, T.; Wong, M. K. C.; Tetrahedron 1996, 52, 6307.

6. Kim, S. H.; Oh, S. M.; Kim, T. S.; Eur. J. Pharmacol. 2005, 511,89 .

7. Romo, J.; Joseph-Nathan, P.; Díaz, F. A.; Tetrahedron 1964, 20,79 .

8. Alves, J. C. F.; Fantini, E. C.; J. Braz. Chem. Soc. 2005, 16, 749.

9. For a survey on the conformational analysis of hydroazulenes see: Hendrickson, J. B.; Tetrahedron 1963, 19, 1387; De Clercq, P. J.; J. Org. Chem. 1981, 46, 667; De Clercq, P. J.; Tetrahedron 1981, 37, 4277.

10. Fantini, E. C.; Rabi, J. A.; Cienc. Cult. 1985, 37 (7 Supl.), 417.

11. Fantini, E. C.; PhD Thesis, Universidade Federal do Rio de Janeiro, Brazil, 1985.
12. Fantini, E. C.; Rabi, J. A.; Cienc. Cult. 1983, 35 (7 Supl.), 403.

13. Maçaira, L. A.; Garcia, M.; Rabi, J. A.; J. Org. Chem. 1977, 42, 4207.

14. Fantini, E. C.; Ferreira, J. L. P.; Rabi, J. A.; J. Chem. Res. (S), 1986, 298.

15. Fantini, E. C.; Rabi, J. A.; Cienc. Cult. 1986, 38 (7 Supl.), 521.

16. Cambridge Soft Corporation; CS Chem3D Ultra 7.0, Molecular Modeling and Analysis; Cambridge, 2001.

17. Ferreira, J. L. P.; M.Sc. Dissertation, NPPN, Universidade Federal do Rio de Janeiro, Brazil, 1985.

18. Alves, J. C. F.; M.Sc. Dissertation, Universidade Federal Rural do Rio de Janeiro, Brazil, 1993.

19. Boucheron, C.; Compain, P.; Martin, O. R.; Tetrahedron Lett. 2006, 47, 3081.

20. Krishna, P. R.; Reddy, P. V. N.; Tetrahedron Lett. 2006, 47, 4627.

21. Kocalka, P.; Pohl, R.; Rejman, D.; Rosenberg, I.; Tetrahedron 2006, 62, 5763.

22. Lansbury, P. T.; Vacca, J. P.; Tetrahedron 1982, 38, 2797.

23. Hendrickson, J. B.; J. Am. Chem. Soc. 1967, 89, 7047.

24. Fischer, N. H.; Wu-Shih, Y. F.; Chiari, G.; Fronczek, F. R.; Watkins, S. F.; J. Nat. Prod. 1981, 44, 104 and references cited therein.

25. Perrin, D. D.; Armarego, W. L. F.; Perrin, D. R.; Purification of Laboratory Chemicals, $2^{\text {nd }}$ ed.; Pergamon Press Ltd: New York, 1980 .

Received: October 17, 2006 Web Release Date: May 21, 2007 


\title{
Study of the Inversion Reaction of the Lactonic Fusion on Eremanthine Derivatives
}

\author{
José C. F. Alves* and Edna C. Fantini ${ }^{\dagger}$ \\ Departamento de Química, Instituto de Ciências Exatas, Universidade Federal Rural do \\ Rio de Janeiro, 23890-970 Seropédica-RJ, Brazil
}

This supplementary material displays some stereochemical aspects of the lactonic fusion inversion presented in the main text of the article.

After opening the lactonic ring on starting materials with trans fusion in basic medium, followed by mesylation stage, the carboxylates can present themselves in different conformations as rotamers (Scheme S1). In order to compare the relative stabilities of the starting materials 8-13, their correspondent reactive carboxylates (mesylates at C-6 position) and products with stereochemical inversion at the alkoxy carbon, we elaborated Table S1 containing the steric energies for these conformers. We used the MM2 program and then the three-dimensional structures of carboxylates from the models 8-13 in Table S1, displaying less steric interactions (Figures S1-9). After data analysis (shown in Table S1 and three-dimensional structures of carboxylates), we can assume:

(i) all conformers with less steric interactions of the opened lactonic rings, marked with asterisk in Table S1, have smaller steric energies than their respective substrates with trans lactonic fusion;

(ii) the two epimers 32a-b have less steric interactions than their correspondent substrates 8a-b. Such fact, associated with the favorable geometry of the carboxylates to nucleophylic attack on C-6 positions, observed in their three-dimensional structures (Figures S1-2), should have contributed to the better conversion rate of products with cis fusion (32a-b);

(iii) for the model 9, the steric interactions on the conformers with cis lactonic fusion (34a-c) are larger than those of the respective substrates with trans fusion (9a-c), so that the reaction yielding products with configuration inversion on C-6 position should be disfavored, and this must have contributed for the lower conversion rate of epimeric products $\mathbf{3 4 a - c}$;

(iv) in model 10, the steric interactions of epimer $\mathbf{3 6}$ are smaller than those of the substrate, however the boat

*e-mail: alvesjcf@yahoo.com.br

$\dagger$ Deceased in 1993

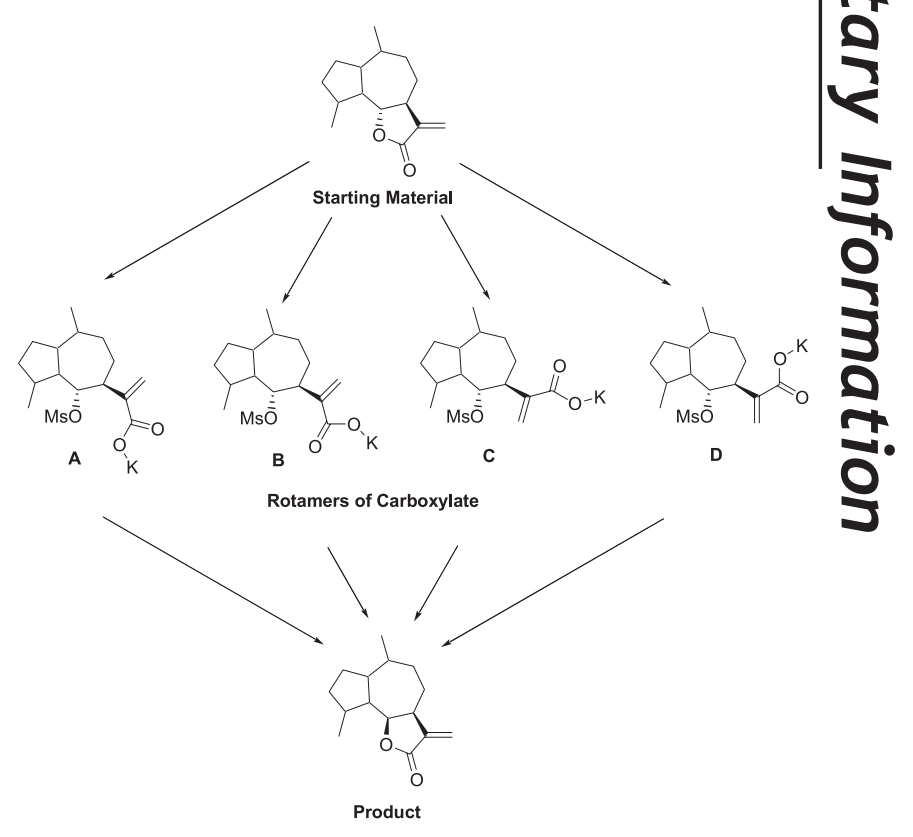

Scheme S1

$\left(\mathrm{B}_{8}\right)$ conformation of the final product is less stable than the twist-chair $\left(\mathrm{TC}_{8}\right)$ conformation of the initial substrate (Table 6 in the main text). Such fact should disfavor the formation of product $\mathbf{3 6}$, leading to a larger proportion of product with trans lactonic fusion in relation to one with cis lactonic fusion;

(v) among the models submitted to conditions of lactonic fusion inversion, the carboxylate derived from allylic acetate $\mathbf{1 1}$ was the one which presented less steric interactions (Table S1). As this intermediate has few steric interations, the intermolecular nucleophylic substitution must have been favored to generate polymeric chains formation;

(vi) concerning model 12, the steric interations between substrate and epimeric product (40) are similar. However, conformation changes between substrate $\left(\mathrm{C}_{5}\right)$ and product $\left(\mathrm{C}_{7}\right)$ ( Table 6 in the main text) should be possibilities that disfavor the product formation with inversion of configuration on C-6 position;

(vii) the steric interactions on product $\mathbf{2 8}$ with cis 
Table S1. Steric energies for starting materials, rotamers of carboxylates $(\mathbf{A}, \mathbf{B}, \mathbf{C}, \mathbf{D})$ and products of the reactions of lactonic fusion inversion of models 8-13

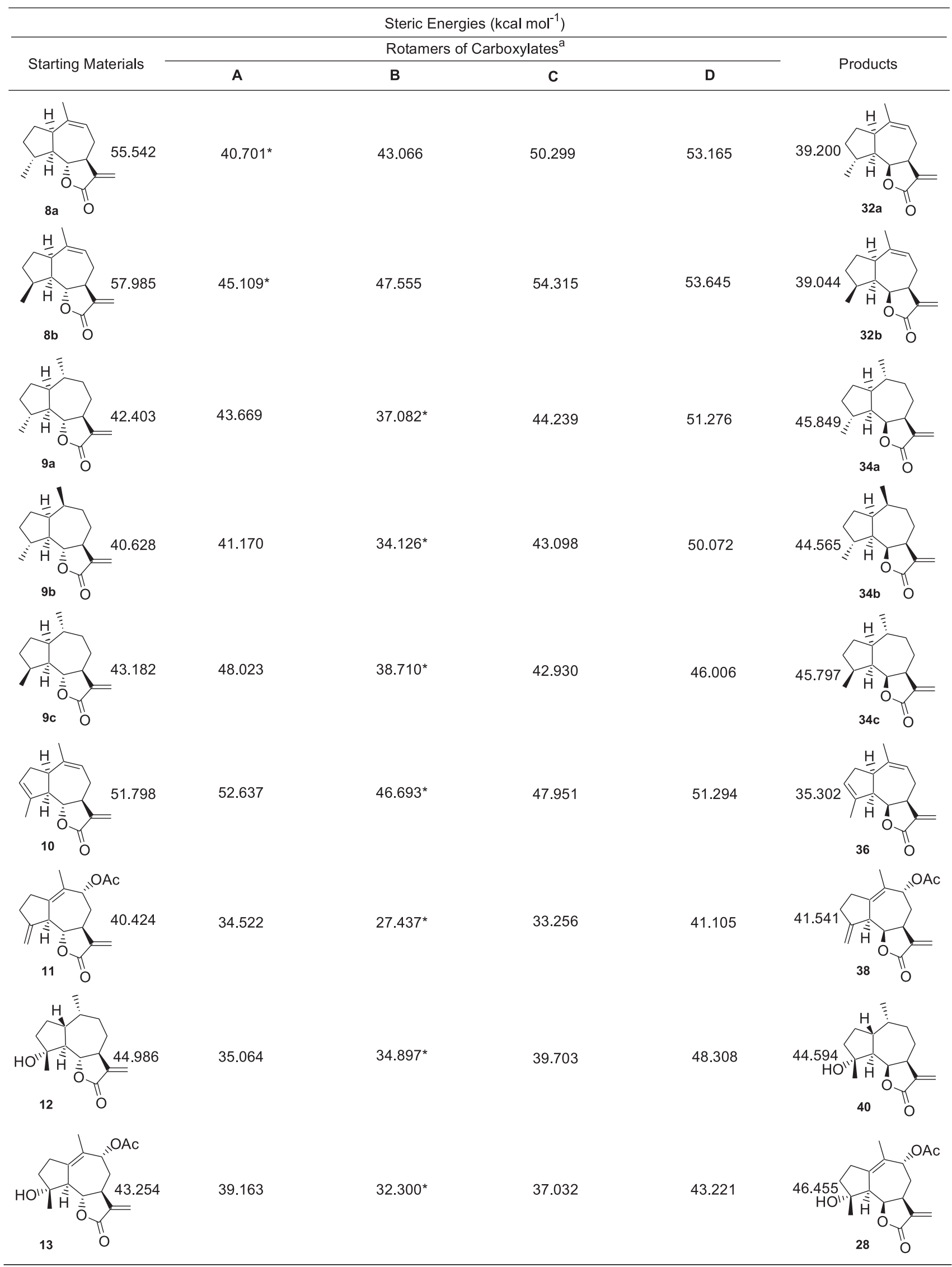


lactonic fusion are higher than the ones on substrate $\mathbf{1 3}$ However, model 13 and its correspondent epimer $\mathbf{2 8}$ have the same conformations at the seven-membered ring $\left(\mathrm{C}_{7}\right)$ (Table 6 in the main text), so that, there is no process of conformational interconversion. This factor must have favored the best result obtained by this substance during the lactonic inversion reaction in relation to other models evaluated in this study.

Qualitative graphics correlating steric energy (SE) with the coordinate of the lactonic inversion reaction to the substrates with trans lactonic fusion (A), reactive intermediate mesylates $(\mathbf{B})$ and products with cis lactonic fusion (C) (Scheme S2) for the models 8-13 are depicted in Figures S10-12.

An intriguing result was obtained in the ${ }^{1} \mathrm{H}$ NMR spectrum of crude product from the reaction of lactonic fusion inversion of model 8 ( Table 4 - Exp. 1, in the main text). After analysis of this spectrum we verified atypical values of chemical shifts for the hydrogens H-13 (deshielded) and H-9 (shielded) for the compounds 32,

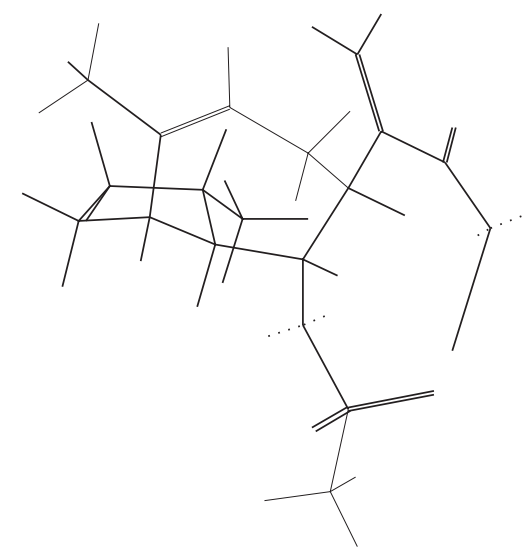

8a-A

Figure S1. Three-dimensional structure of reactive carboxylate (mesylate at C-6 position) of model 8a with less steric interactions.

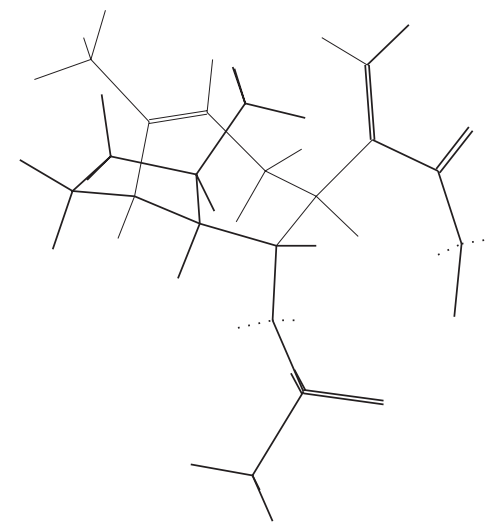

$\mathbf{8 b}-\mathbf{A}$

Figure S2. Three-dimensional structure of reactive carboxylate (mesylate at C-6 position) of model $\mathbf{8 b}$ with less steric interactions. not exhibited before in eremanthine derivatives. After analysis of three-dimensional structures of compounds 32a-b with cis lactonic fusion (Figures S14-15), we verified space proximity of hydrogens H-13 with the deshielding area of double bond $\mathrm{C} 9-\mathrm{C} 10$ and the proximity of hydrogen H-9 with the shielding area of $\alpha$-methylene$\gamma$-lactone. The comparison of three-dimensional structures of compounds 32a-b (Figures S14-15), that have double bond at C9-C10 and cis lactonic fusion, with the similar compound 6-epi-isoeremanthine (36) that differs from 32a-b only in the unsaturation degree at C3-C4 (Figure $\mathrm{S} 13)$, contributed to confirm this atypical data of ${ }^{1} \mathrm{H}$ NMR obtained with these compounds. In the three-dimensional structure of compound 36 (Figure S13) we verified that there is no space proximity of hydrogens H-9 and H-13 with the shielding/deshielding areas of double bonds mentioned for compounds 32a-b. These conformational differences observed in the three-dimensional structures of the mentioned compounds must be the cause of atypical results obtained in their ${ }^{1} \mathrm{H}$ NMR spectra.

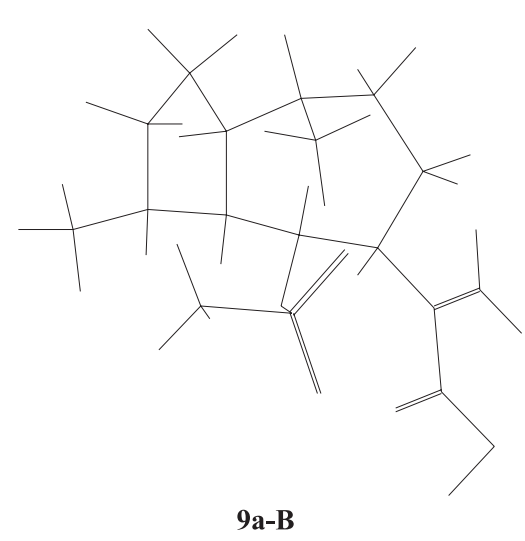

Figure S3. Three-dimensional structure of reactive carboxylate (mesylate at C-6 position) of model 9a with less steric interactions.

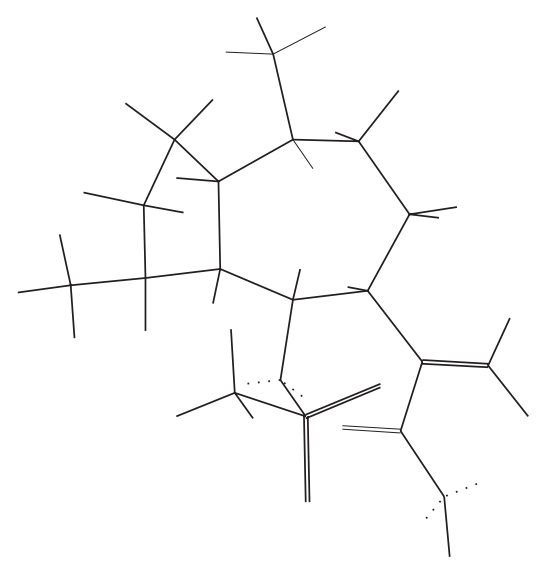

9b-B

Figure S4. Three-dimensional structure of reactive carboxylate (mesylate at C-6 position) of model $\mathbf{9 b}$ with less steric interactions. 


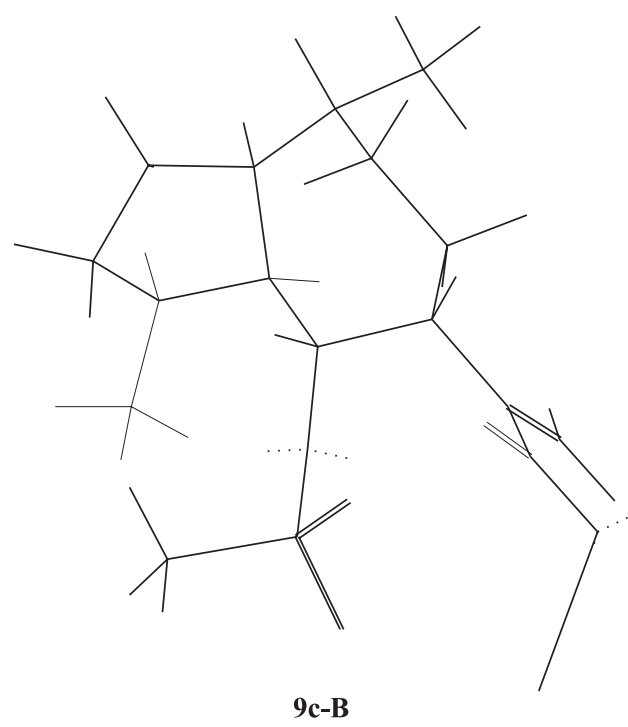

Figure S5. Three-dimensional structure of reactive carboxylate (mesylate at C-6 position) of model $\mathbf{9 c}$ with less steric interactions.

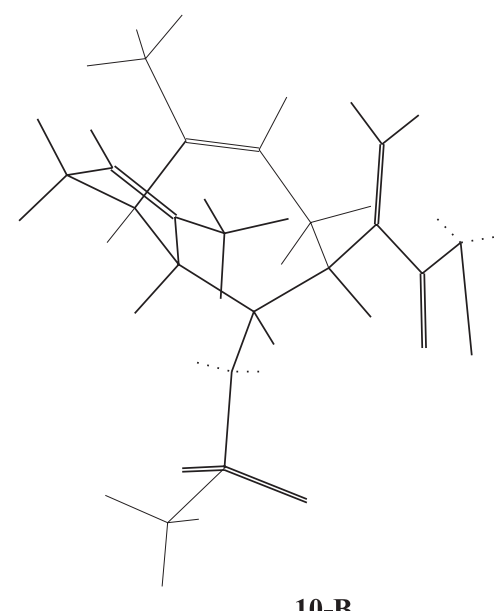

Figure S6. Three-dimensional structure of reactive carboxylate (mesylate at C-6 position) of model $\mathbf{1 0}$ with less steric interactions.

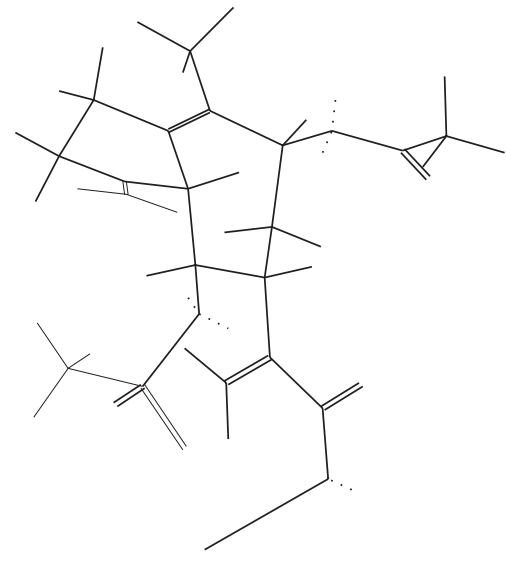

11-B

Figure S7. Three-dimensional structure of reactive carboxylate (mesylate at C-6 position) of model $\mathbf{1 1}$ with less steric interactions.

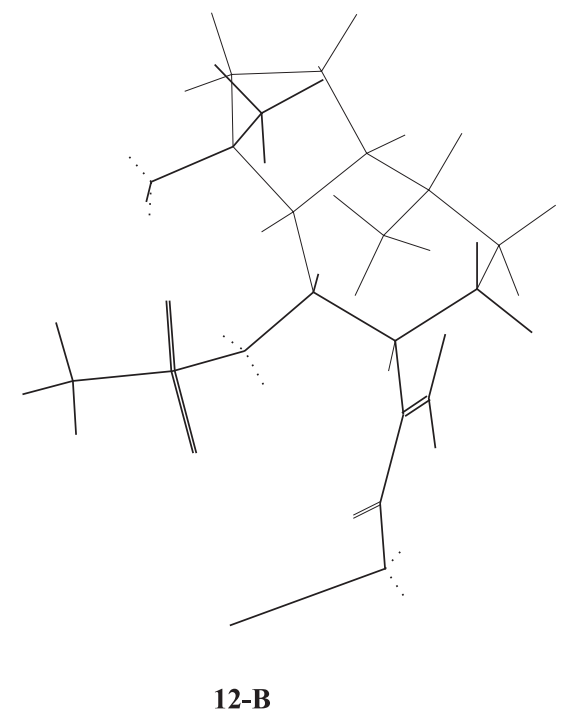

Figure S8. Three-dimensional structure of reactive carboxylate (mesylate at C-6 position) of model $\mathbf{1 2}$ with less steric interactions.

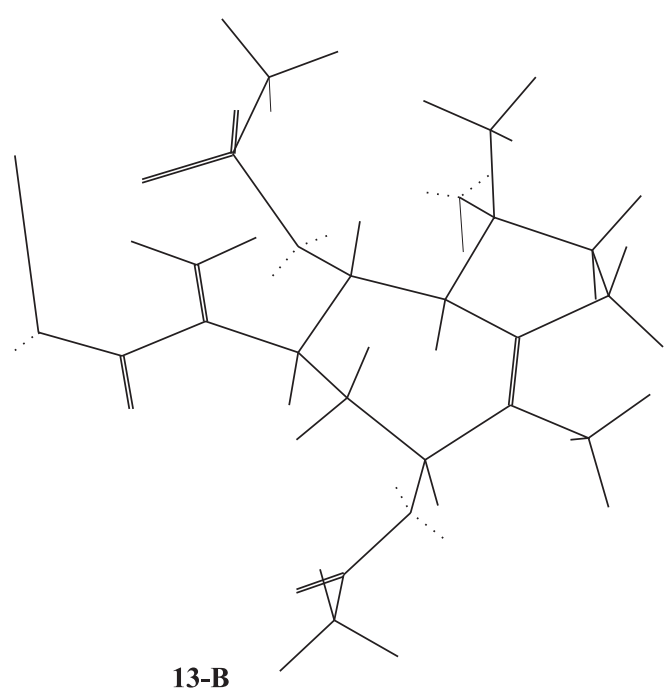

Figure S9. Three-dimensional structure of reactive carboxylate (mesylate at C-6 position) of model $\mathbf{1 3}$ with less steric interactions.

\section{General Reaction}

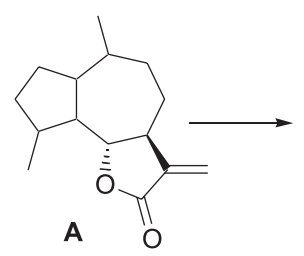<smiles>C=C1C(=O)O[C@H]2C1CCC(C)C1CCC(C)C12</smiles>

Scheme S2 


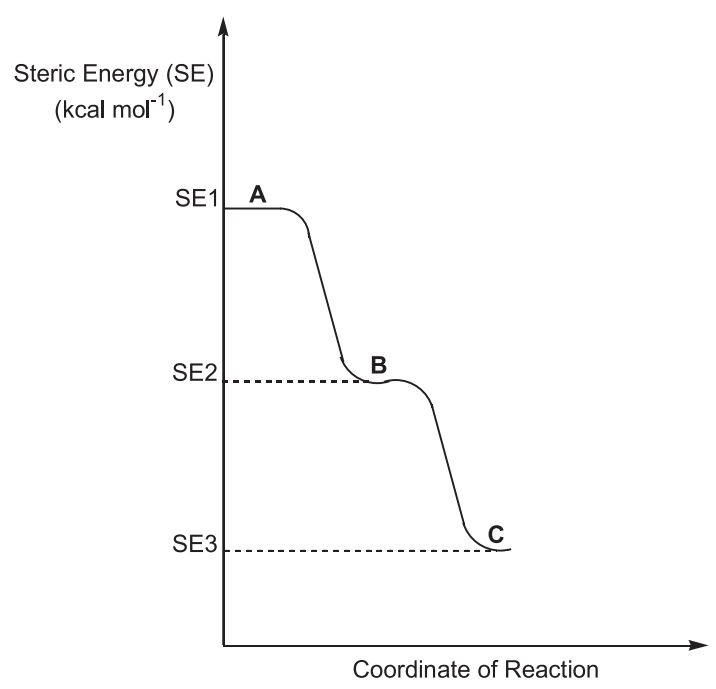

Figure S10. Qualitative graphic of steric energy (SE) versus coordinate of reaction for models $\mathbf{8} \mathbf{a}-\mathbf{b}$ and $\mathbf{1 0}$.

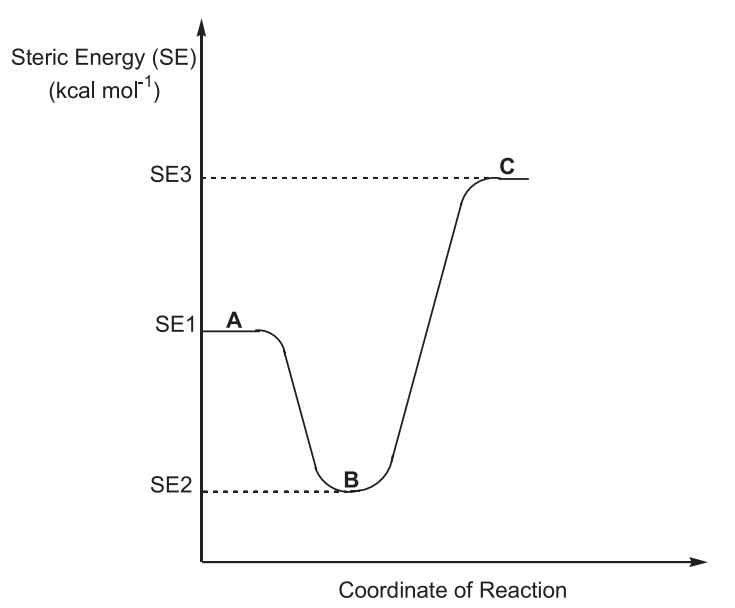

Figure S11. Qualitative graphic of steric energy (SE) versus coordinate of reaction for models $\mathbf{9 a - c , 1 1}$ and $\mathbf{1 3}$.

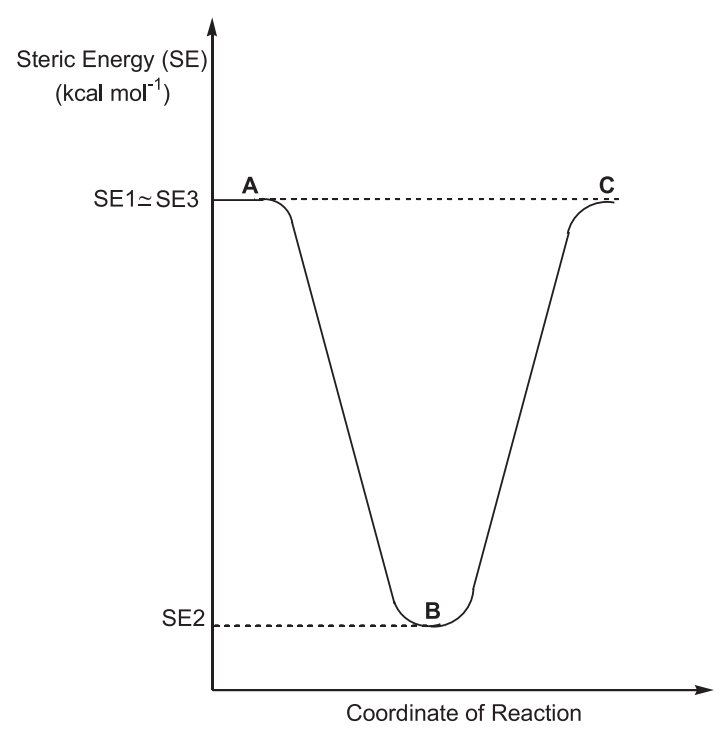

Figure S12. Qualitative graphic of steric energy (SE) versus coordinate of reaction for model $\mathbf{1 2}$.
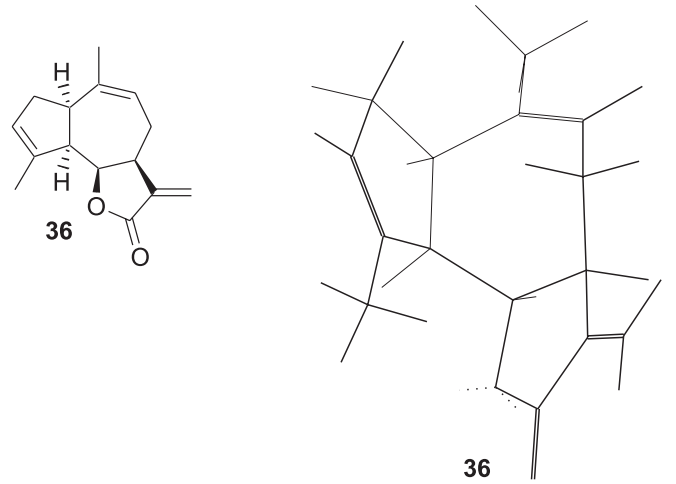

Figure S13. Three-dimensional structure of 6-epi-isoeremanthine (36).
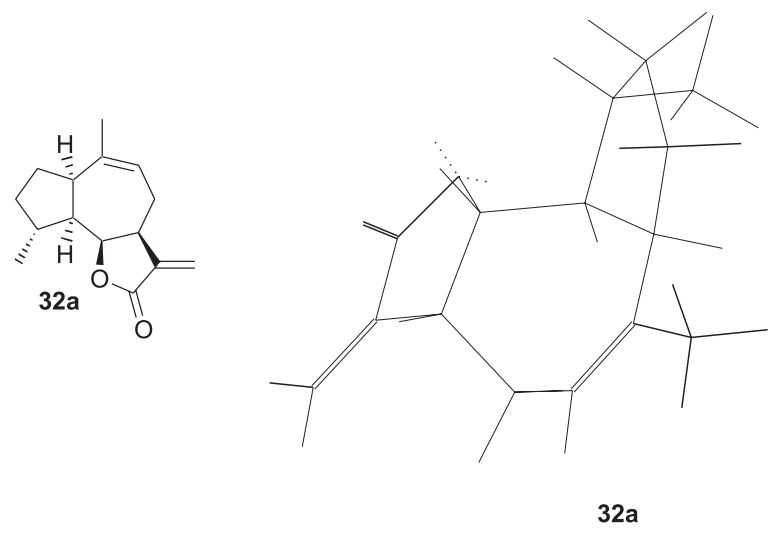

Figure S14. Three-dimensional structure of compound 32a.
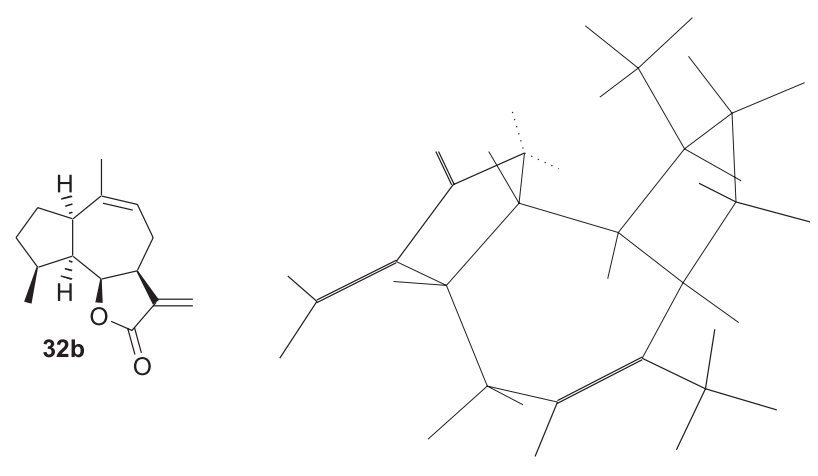

$32 b$

Figure S15. Three-dimensional structure of compound 32b. 